Article

\title{
National Culture and Tax Avoidance of Multinational Corporations
}

\author{
Ji Seon Yoo ${ }^{1, *(\mathbb{D})}$ and Ye Ji Lee ${ }^{2}$ \\ 1 Division of Business Administration, Hoseo University, Chungcheongnam-do 31066, Korea \\ 2 Graduate School of Science in Taxation, University of Seoul, Seoul 02504, Korea; yeji0320@hanmail.net \\ * Correspondence: jsyoo@hoseo.ac.kr
}

Received: 17 October 2019; Accepted: 4 December 2019; Published: 5 December 2019

check for updates

\begin{abstract}
This study tests the role of national culture in tax avoidance by multinational corporations (MNCs). Hofstede's four cultural dimensions are used to measure cultural differences across countries: uncertainty avoidance, individualism, masculinity, and power distance. The empirical results of the study imply that MNCs headquartered in countries with low uncertainty avoidance, low individualism, high masculinity, and low power distance engage in a higher level of tax avoidance than MNCs in countries with high uncertainty avoidance, high individualism, low masculinity, and high power distance. In addition, the cultural features of the parent company generally have a stronger influence on group-level tax avoidance than those of its subsidiaries. This study contributes to the literature by presenting empirical evidence of culture as a determinant of tax avoidance by MNCs.
\end{abstract}

Keywords: effective tax rate; Hofstede's cultural dimensions; multinational corporations; nontax factor; tax avoidance

\section{Introduction}

Despite the general consensus that culture is an integral determinant of behaviors of individuals and organizations, culture has received little attention from researchers because of difficulty in designing testable hypotheses (Guiso et al. [1]). With a development in data and measurement, a growing number of studies have recently investigated the role of national culture on economic outcomes and decisions (North [2]; Guiso et al. [1]; Alesina and Giuliano [3]; Brochet et al. [4]; Doidge et al. [5]). In the field of tax accounting, a few studies identify that national culture influence tax avoidance of individuals and firms (Tsakumis et al. [6]; Richardson [7]; Richardson [8]; Bame-Aldred et al. [9]).

Tax avoidance by multinational corporations (MNCs) has become a topic of public controversy since the early 2010s. Because tax avoidance of MNCs impede fair competition of corporations, understanding the nature and determinants of tax avoidance of MNCs is critical to pursuing sustainable economic growth. MNCs operate affiliates in more than one tax jurisdiction that their tax-avoidance behaviors are affected by different national culture. In this respect, culture can be an influential nontax determinant for tax avoidance of MNCs, compared to that of individuals or firms. The relationship between culture and tax avoidance of MNCs, however, has not yet studied by previous studies. The purpose of this study is to fill this void by exploring the role of national culture in MNCs' tax-avoidance behavior.

In this study, Hofstede's framework is applied to measure the cultural dimensions of countries. Hofstede [10] initially proposed the following four dimensions representing the independent preferences for one state of affairs over another that distinguish countries from each other: The uncertainty avoidance index (UAI), individualism versus collectivism (IDV), masculinity versus femininity (MAS), and the power distance index (PDI). 
UAI indicates the degree to which the members of a society feel uncomfortable with uncertainty and ambiguity. The previous literature finds that UAI is positively associated with individuals' tax evasion levels (Tsakumis et al. [6]; Richardson [8]). However, the opposite effects of UAI are more intuitive because members of MNCs that are uncomfortable with unpredictable tax challenges from tax authorities would deter aggressive tax planning.

IDV refers to the degree to which people in a society are integrated into groups. The previous literature provides evidence that IDV is negatively associated with tax avoidance; that is, more collectivist societies engage in a higher level of tax avoidance than more individualist societies because collectivist societies' concern for the in-group can override written laws (Husted [11]).

The masculinity component of the MAS dimension represents a preference for achievement, heroism, assertiveness, and material rewards for success. Femininity oppositely refers to a preference for cooperation, modesty, caring for the weak, and quality of life. The previous literature suggests that individuals in highly masculine countries engage in tax-avoidance activities to a lesser extent than those in less-masculine countries (Tsakumis et al. [6]; Richardson [8]). However, according to findings of Hofstede [11], MNCs in masculine countries that are oriented toward success and achievement will instead participate in more aggressive tax planning to achieve high performance compared with less-masculine countries.

Lastly, PDI represents the extent to which less-powerful members of organizations and institutions accept and expect that power is distributed unequally. Tsakumis et al. [6] and Richardson [8] suggest that individuals in countries with high PDI participate in aggressive tax avoidance. According to the findings of Hofstede [12], however, members in MNCs in countries with high PDI are less sensitive to the fairness of taxation, leading to a lower level of tax avoidance.

In this study, a sample of group years of international MNCs is used. Group-year observations are used instead of firm-year observations to investigate the cultural effects on group-level tax avoidance. Ownership and financial data of multinational parents and subsidiaries are collected from Bureau van Dijk's Orbis database. The financial data of a parent and its controlling subsidiaries are aggregated to form each group year. The final sample of group years comprises 36,235 observations domiciled in 31 countries for the years 2008 to 2015.

Four cultural dimensions (UAI, IDV, MAS, and PDI) of countries are used as independent variables. For the dependent variable, worldwide generally accepted accounting principle effective tax rates (worldwide GAAP ETRs) of MNCs are used as a proxy for TAXAVOIDANCE. Worldwide GAAP ETRs of MNCs are estimated based on aggregated financial data of the parent company and its subsidiaries. TAXAVOIDANCE is regressed on four cultural dimensions for parent and subsidiary countries, respectively, to test the effects of culture on MNCs' tax avoidance.

The results of the empirical analysis show that MNCs in countries with a lower (higher) level of UAI, lower (higher) level of IDV, higher (lower) level of MAS and lower (higher) level of PDI engage in a higher (lower) level of tax avoidance by reporting lower (higher) worldwide GAAP ETR. It is also observed that the cultural features of the parent generally have a stronger influence on group-level tax avoidance than those of its subsidiaries. The results are generally supported by a series of robustness tests.

Tax avoidance is generally considered as a behavioral problem in the financial sector. In a broad sense, however, tax avoidance can be seen as a sustainability problem because it erodes the public, regulatory, and organizational commons that are required for sustainable conservation [13]. Therefore, comprehensive understanding of tax avoidance behavior can lead to achieving sustainable economic growth.

In this light, this study contributes to investigate a previously unexplored area of cultural effects on tax avoidance by MNCs. Several studies have investigated the association between culture and tax avoidance by individuals or domestic firms. However, no attempt has been made to investigate the effects of the cultural characteristics of countries on tax avoidance by MNCs. This study provides empirical evidence that culture is one of the determinants of MNCs' tax-avoidance behavior. Given the 
scarce number of studies investigating the relationships between nontax factors and the tax decisions of MNCs, the present study contributes in extending this line of research, and in providing in-depth information on MNCs' tax-avoidance behavior.

In addition, this study provides important evidence that the effects of the features of the home country on group-level tax aggressiveness dominate those of the subsidiaries' countries. Policymakers should, therefore, consider the cultural aspects of headquarter countries when adopting anti-avoidance laws or regulation for MNCs. Sophisticated regulations encompassing cultural effects will contribute to obtaining sustainable economy.

This study is organized as follows: Section 2 reviews the relevant literature, introduces Hofstede's cultural dimensions, and develops the hypotheses. Section 3 describes the sample and explains the research design and variables used. Section 4 reports and discusses the results of the hypothesis testing, as well as the robustness tests. Lastly, Section 5 provides the conclusions of the study.

\section{Background and Hypotheses}

\subsection{National Culture and Tax Avoidance}

Identifying determinants of tax avoidance is one of the most important and widely investigated areas of tax-accounting research. Several studies have investigated the effects of nontax features on firm-level tax avoidance. For example, Law and Mills [14] and Edwards et al. [15] recognize that financially constrained firms participate in tax planning as a way to secure funds. Under an international setting, Riahi-Belkaoui [16] and Picur and Riahi-Belkaoui [17] find that competition laws, economic freedom, the importance of equity markets, the incidence of violent crimes, bureaucracy levels, corruption control and tax morale are related to tax compliance. Akhtar et al. [18] find evidence that certain firm-level and country-level governance measures influence MNCs' motivations for tax evasion. Richardson [7] also finds that non-economic factors, such as the complexity of the tax system, education, income source, fairness and tax morale are key determinants of tax evasion.

National culture may represent another important nontax factor for tax-avoidance behaviors, and the association between national culture and tax avoidance has recently been explored by researchers. Relevant prior studies can be divided into two categories depending on the subjects of tax avoidance: Individuals and corporations.

\subsubsection{National Culture and Individual's Tax Avoidance}

Earlier studies generally focus on identifying the relationship between national culture and individuals' tax noncompliance. Using an experimental method, Alm et al. [19] examine the major economic and noneconomic factors that affect tax compliance. They find that social norms are important determinants of tax avoidance in Spain and the United States. Cummings et al. [20] investigate the association between cultural differences and tax compliance using experimental and survey data from the United States, Botswana, and South Africa. Their results show that differences in tax-compliance levels across countries are primarily attributable to differences in the fairness of tax administration, perceived equity of the fiscal exchange, and overall attitude toward the government. Alm and Torgler [21] analyze the differences in tax morale and tax compliance between the United States and 15 European countries. Tax morale is measured using information from the World Values Survey. They find that individuals in the United States have the highest tax morale across all countries.

Tsakumis et al. [6] examine the influence of national culture on tax-compliance levels across countries using the cultural dimensions developed by Hofstede [10]. They measure the level of a country's tax evasion using an economic estimate of underreported income within a country in accordance with prior studies (e.g., Riahi-Belkaoui [16]; Alm and Torgler [21]). They find that each cultural dimension influences the level of tax evasion of countries. Specifically, individuals in countries with higher UAI, lower IDV, lower MAS, and higher PDI participate in tax evasion to a greater extent than those in countries with opposite cultural features. 
Richardson [8] extends the work of Tsakumis et al. [6] using multiple measures of tax evasion. Specifically, the study uses the following three proxies for measuring tax avoidance: (i) A country measure of the shadow economy reported by the World Economic Forum (WEF); (ii) a country measure of tax evasion reported by the WEF with data averaged and transformed for 2002-2004; and (iii) a country measure of tax evasion reported by the Institute of Management Development. He also controls for other legal, political, and religious country effects. Consistently, he identifies that the higher the level of UAI and the lower the level of IDV result in the higher the level of tax evasion across countries. However, he finds no significant impact of PDI or MAS on tax evasion. Richardson [8] explains that the results of Tsakumis et al. [6] may have omitted variable bias because variables pertaining to legal enforcement, trust in government, and religiosity are not included in their model.

In summary, several studies have explored the role of national culture in individuals' tax avoidance and noncompliance. Recent studies consider various aspects and dimensions of national culture by employing Hofstede's cultural framework. However, two studies using Hofstede's cultural dimensions (Tsakumis et al. [6]; and Richardson [8]) show conflicting results for certain dimensions.

This study uses Hofstede's cultural dimensions consistent with two previous studies. The present study, however, can be discriminated from the previous studies in that it analyzes the relationship between national culture and tax avoidance by MNCs, not individuals. Because the tax-avoidance decisions of MNCs with a large number of controlling affiliates will differ from those of individuals, this study extends the line of research by exploring the relationship between national culture and tax avoidance by MNCs.

\subsubsection{National Culture and Corporate Tax Avoidance}

Compared with the influence of national culture on individuals' tax avoidance, the impact of national culture on corporate tax avoidance has received little attention. In fact, only Bame-Aldred et al. [9] examine the linkage between culture and firm-level tax evasion. Bame-Aldred et al. [9] specifically test whether national culture continues to influence tax evasion after controlling for institutional, demographic, and attitudinal country-level factors using hierarchical linear modeling (HLM).

The responses of firm participants to the World Business Environment Survey (WBES) are used as the measure of tax evasion. It is important to note that this dependent variable of tax evasion indicates firms' likelihood of tax evasion and not an actual behavior or consequence of evasion. As independent variables, they use the following four cultural dimensions highlighted by institutional anomie theory: individualism, achievement, assertiveness and humane orientation. Based on responses from more than 3000 firms in 31 countries, they identify that firms in countries with high individualism, low achievement orientation, and low assertiveness are likely to resort to deviant behaviors like tax evasion. Firms in countries with high humane-oriented values are less likely to engage in tax evasion.

One may question how country-level features affect firm-level decisions. However, a series of research identify significant relationships between culture (measured using Hofstede's cultural dimensions), and firm-level decisions, including disclosure (Gray and Vint [22], Hope [23]), financial reporting (Hussein [24]), auditor choice (Chan et al. [25]), and investment efficiency (Zhang et al. [26]). Because managers and employees are one of the most important and valuable resources for corporations, the cultural background of these members will influence corporate culture, and consequently, the decisions of the corporations. Brochet et al. [4] find that managers' ethnic cultural background affects communication with investors and the disclosure attributes. Their study confirms the existence of the linkage between culture and firm-level actions.

Bame-Aldred et al. [9] and the present study both investigate the influence of national culture on tax avoidance by firms. However, the present study differs in a number of aspects. First, the present study examines tax avoidance by MNCs and not individual firms. Specifically, it tries to identify whether the cultural profile of the parent country and/or those of the subsidiaries' countries impact tax avoidance by the MNC group. Given the significance of the rapidly increasing tax aggressiveness of MNCs in recent years, this study contributes by identifying the determinants of MNCs' tax-avoidance behaviors. 
Second, the present study uses worldwide GAAP ETR values calculated based on firms' actual financial performance to measure the level of tax avoidance. In general, GAAP ETR captures broader tax-avoidance activities of MNCs compared with other measures of tax avoidance. The results of this study, therefore, show whether the cultural profile of a country influences MNCs to avoid taxes by effectively reducing their tax burden. On the contrary, Bame-Aldred et al. [9] investigate whether the cultural profile of a country impacts the likelihood of tax evasion by firms.

Lastly, the present study uses the most recent financial data of MNCs for the period of 2008 to 2015. The Organisation for Economic Co-operation and Development (OECD) launched the so-called Base Erosion and Profit Shifting (BEPS) project in 2012 to tackle international tax avoidance by MNCs (OECD [27]). After the launch in 2012 of the OECD's BEPS action plan, the tax-avoidance behavior of MNCs may have changed significantly. Therefore, it is critical to include post-2012 financial data in the analysis to reflect the most recent trends in MNC tax avoidance.

\subsection{Hofstede's Cultural Dimensions and Hypothesis Development}

A number of papers provide distinct categories or frameworks of culture. For example, Cattell [28] compares the national cultures of countries using factor analysis. Gregg and Banks [29] study aspects of political systems; Adelman and Morris [30] examine interactions among economic growth, social culture, and political variables; Lynn [31], and Lynn and Hampson [32] measure national differences in mental health from demographic and epidemiological data.

This study uses Hofstede's cultural dimensions as independent variables for tax avoidance because it represents one of the most widely applied and long-investigated frameworks. Hofstede's cultural dimensions is a framework initially developed by Geert Hofstede, which describes the effects of a society's culture on the values of its members. Hofstede initially developed the model based on a worldwide survey of employee values by International Business Machines Corporation (hereafter IBM). Hofstede's cultural dimensions theory is generally accepted as the most comprehensive framework on national cultures in the field of international business, including business negotiation, marketing, communication, etc.

Hofstede [10] initially proposed four dimensions (i.e., UAI, IDV, MAS, and PDI). The most recent version of Hofstede's framework in 2010 (Hofstede [33]) extends his previous dimensions by including two other cultural dimensions: Indulgence (IND) and long-term orientation (LTO). In this study, only the original four dimensions are considered as independent variables because of the supplementary nature of the two newly introduced dimensions and to maintain consistency with the financial data of sample observations used in this study (i.e., 2008 to 2015).

The following part of this section explains each of the cultural dimensions and develops hypotheses.

\subsubsection{Uncertainty Avoidance Index (UAI)}

UAI indicates the degree to which members of a society feel uncomfortable with uncertainty and ambiguity. Hofstede [12] explains that uncertainty avoidance differs from risk avoidance by expressing the extent to which members of a society feel uncomfortable in novel, unknown, or surprising situations. Members of societies with high uncertainty avoidance tend to suppress the possibility of such situations by adopting strict behavioral codes, laws and rules, disapproval of deviant opinions, and a belief in absolute truth. Hofstede [12] provides some examples of differences between weak uncertainty avoidance and strong uncertainty avoidance. In a society with weak uncertainty avoidance, members are tolerant of deviant persons and ideas; comfortable with ambiguity and chaos; hostile to laws; and seen as competent towards authorities. By contrast, members of a society with strong uncertainty avoidance are intolerant of deviant persons and ideas; prefer clarity and structure; have an emotional need for rules; and are seen as incompetent towards authorities.

Hofstede Insights (https://www.hofstede-insights.com) periodically updates Hofstede's cultural dimension scores. This study uses the most recent scores of Hofstede's cultural dimensions reported by Hofstede in 2010. Due to the nature of national data, the cultural dimension scores are not expected to 
vary significantly from year to year. Table 1 reports the scores of the cultural dimension of the 31 sample countries. Greece has the highest UAI score, 112, while Denmark has the lowest, 23. The average UAI score is 69.06 .

Table 1. Hofstede's cultural dimension scores of 31 sample countries.

\begin{tabular}{|c|c|c|c|c|c|}
\hline No. & Country & UAI & IDV & MAS & PDI \\
\hline 1 & Australia & 51 & 90 & 61 & 38 \\
\hline 2 & Austria & 70 & 55 & 79 & 11 \\
\hline 3 & Belgium & 94 & 75 & 54 & 65 \\
\hline 4 & Canada & 48 & 80 & 52 & 39 \\
\hline 5 & Chile & 86 & 23 & 28 & 63 \\
\hline 6 & Czech Republic & 74 & 58 & 57 & 57 \\
\hline 7 & Denmark & 23 & 74 & 16 & 18 \\
\hline 8 & Estonia & 60 & 60 & 30 & 40 \\
\hline 9 & Finland & 59 & 63 & 26 & 33 \\
\hline 10 & France & 86 & 71 & 43 & 68 \\
\hline 11 & Germany & 65 & 67 & 66 & 35 \\
\hline 12 & Greece & 112 & 35 & 57 & 60 \\
\hline 13 & Hungary & 82 & 80 & 88 & 46 \\
\hline 14 & Ireland & 35 & 70 & 68 & 28 \\
\hline 15 & Italy & 75 & 76 & 70 & 50 \\
\hline 16 & Japan & 92 & 46 & 95 & 54 \\
\hline 17 & Luxembourg & 70 & 60 & 50 & 40 \\
\hline 18 & Mexico & 82 & 30 & 69 & 81 \\
\hline 19 & Netherlands & 53 & 80 & 14 & 38 \\
\hline 20 & New Zealand & 49 & 79 & 58 & 22 \\
\hline 21 & Norway & 50 & 69 & 8 & 31 \\
\hline 22 & Poland & 93 & 60 & 64 & 68 \\
\hline 23 & Portugal & 104 & 27 & 31 & 63 \\
\hline 24 & $\begin{array}{l}\text { Republic of } \\
\text { Korea }\end{array}$ & 85 & 18 & 39 & 60 \\
\hline 25 & Slovakia & 51 & 52 & 110 & 104 \\
\hline 26 & Slovenia & 88 & 27 & 19 & 71 \\
\hline 27 & Spain & 86 & 51 & 42 & 57 \\
\hline 28 & Sweden & 29 & 71 & 5 & 31 \\
\hline 29 & Switzerland & 58 & 68 & 70 & 34 \\
\hline 30 & Turkey & 85 & 37 & 45 & 66 \\
\hline \multirow[t]{4}{*}{31} & United States & 46 & 91 & 62 & 40 \\
\hline & Average & 69.06 & 59.45 & 50.84 & 48.74 \\
\hline & Minimum & 23 (Denmark) & 18 (Rep. of Korea) & 5 (Sweden) & 11 (Austria) \\
\hline & Maximum & 112 (Greece) & 91 (United States) & 110 (Slovakia) & 104 (Slovakia) \\
\hline
\end{tabular}

(1) UAI stands for uncertainty avoidance index which indicates the degree to which members of a society feel uncomfortable with uncertainty and ambiguity; (2) IDV stands for individualism which indicates the degree to which members of a society are integrated into groups; (3) MAS stands for masculinity which indicates a preference for achievement, heroism, assertiveness, and material rewards for success; (4) PDI stands for power distance index which indicates the extent to which less-powerful members of organizations and institutions accept and expect that power is distributed unequally; (5) Scores in this table are obtained from Hofstede [33]

Tsakumis et al. [6] predict that individuals in countries with high uncertainty avoidance lack trust in their government systems, and consequently, are motivated to avoid taxes. Richardson [8] also follows this view, stating that societies with high uncertainty avoidance are rule-oriented societies with complex tax laws and regulations; individuals in such societies are likely to engage in tax evasion because of the positive association between tax complexity and tax evasion (Clotfelter [34]; Richardson [7]; Milliron and Toy [35]; Collins et al. [36]).

The positive association between uncertainty avoidance and tax avoidance found in these two previous studies is, however, counterintuitive in terms of corporate tax avoidance. Because members of countries with high uncertainty avoidance will attempt to circumvent uncertain situations, such as 
tax audits and corresponding sanctions, MNCs in countries with strong uncertainty avoidance would refrain from aggressive tax planning to minimize unexpected challenges by tax authorities. On the contrary, members of MNCs in countries with weak uncertainty avoidance would not be deterred from making aggressive tax decisions because they are comfortable with ambiguity in the future. Therefore, a negative association between uncertainty avoidance and tax avoidance is expected. This study establishes the first hypothesis as follows:

Hypothesis 1 (H1). The uncertainty avoidance (UAI) of a country relates negatively to the level of tax avoidance by an MNC in that country.

\subsubsection{Individualism versus Collectivism (IDV)}

IDV indicates the degree to which members of a society are integrated into groups. Highly individualist countries tend to have loose ties between individuals, who look after themselves and their immediate family. On the contrary, highly collectivist countries have cultures in which people from birth onwards are integrated into strong, cohesive in-groups, often extended families, that continue protecting them in exchange for unquestioning loyalty and oppose other in-groups. In individualist societies, personal opinion is expected; language with the word " $\mathrm{I}$ " is indispensable; the right to privacy is highlighted; and tasks prevail over relationships. On the other hand, in collectivist countries, opinions and votes are generally predetermined by the in-group; language with the word " $\mathrm{I}$ " is avoided; belonging prevails over privacy; and relationships prevail over tasks (Hofstede [12]). As shown in Table 1, US has the highest IDV score, 91, while the Republic of Korea has the lowest, 18. The average IDV score is 59.45 .

Previous studies negatively relate IDV to tax avoidance; they find evidence that members in individualist (collectivist) countries engage in tax avoidance to a lesser (greater) extent than collectivist (individualist) countries. Tsakumis et al. [6] explain that collectivist societies' concern for the in-group can override written laws (Husted [11]) and that they do not view legal norms as universal, whereas, individualist societies hold the view that laws and rights should be equal for all people within a country (Hofstede [37]). Richardson [8] supports this point by noting that tax systems in collectivist countries are likely to be accepted as inequitable and unfair, and thus, individuals tend to evade income taxes (Surrey and McDaniel [38]; Wearing and Headey [39]).

Consistent with previous literature, this paper predicts the negative relation between individualism and the level of tax avoidance by MNCs, leading to the following second hypothesis:

Hypothesis 2 (H2). The individualism (IDV) of a country relates negatively to the level of tax avoidance by an MNC in that country.

However, IDV may have opposite effects on tax avoidance by MNCs because MNCs in highly collectivist countries have to bear high reputational costs when accused of tax avoidance (Hanlon and Slemrod [40]; Graham et al. [41]; Dyreng et al. [42]). Because collectivist countries generally feature higher public scrutiny and pressure on MNCs' tax-avoidance behavior, MNCs in those countries may be deterred from avoiding taxes. Therefore, this study may observe an insignificant or significantly positive relationship between individualism and tax avoidance by MNCs.

\subsubsection{Masculinity versus Femininity (MAS)}

Masculinity represents a preference for achievement, heroism, assertiveness, and material rewards for success. Femininity oppositely refers to a preference for cooperation, modesty, caring for the weak, and quality of life. Countries with high masculinity are generally more competitive, while those with high femininity are more consensus-oriented. As shown in Table 1, masculinity is highest in Slovakia, with a MAS score of 110. Hofstede explains that individuals in Slovakia regard success in 
society as important, and thus, work hard to achieve their goals. Sweden has the lowest MAS score, 5. Individuals in Sweden are, therefore, more modest and caring.

Tsakumis et al. [6] find a negative relationship between MAS and tax evasion in their empirical analysis. They interpret that individuals in highly masculine countries are less likely to engage in tax evasion because they are more conscious of tax compliance. Hofstede [37]'s finding of a negative relationship between MAS and the level of law permissiveness also support this result.

However, Husted [11] provides more intuitive evidence of a positive association of MAS with corruption. He notes that the preference for material success leads to higher participation in corruption. A Prospect Theory study also supports this view by finding that female tax practitioners are more risk-neutral than male tax practitioners (Sanders and Wyndelts [43]), leading to less aggressive tax planning. This study follows the latter view that members (i.e., employees of the parent and subsidiaries) of MNCs in masculine countries that are oriented toward success and achievement participate more in aggressive tax planning to achieve higher performance than those in less-masculine countries.

In this regard, the third hypothesis of this study is stated as follows:

Hypothesis 3 (H3). The masculinity (MAS) of a country relates positively with the level of tax avoidance by an MNC in that country.

\subsubsection{Power Distance Index (PDI)}

PDI represents the extent to which less-powerful members of organizations and institutions accept and expect that power is distributed unequally. Individuals in countries with high power distance accept a hierarchical order and require no further justification. Corruption is rare in these countries because scandals may end political careers. Individuals in countries with low power distance strive to equalize the distribution of power and demand justification for inequalities of power. Corruption is relatively frequent because scandals are generally covered up (Hofstede [12]). Slovakia and Austria have the highest and lowest PDI scores of 104 and 11, respectively.

Two previous studies of Tsakumis et al. [6] and Richardson [8] find a positive relationship between PDI and the level of tax evasion. That is, individuals in countries with high power distance evade more taxes. They argue that individuals in high-power-distance countries perceive tax systems as unfair, and consequently, avoid taxes. However, there is no reasonable connection between high power distance and perception of tax unfairness. According to Hofstede [12], members in societies with high power distance can, in fact, be even less sensitive to the fairness of taxes and any other social systems because they accept inequalities of power and wealth. Therefore, inconsistent with previous literature, this study predicts that the level of power distance negatively affects tax avoidance by MNCs. The last hypothesis is stated as follows:

Hypothesis 4 (H4). The power distance (PDI) of a country relates negatively to the level of tax avoidance by an MNC in that country.

\section{Research Method}

\subsection{Data}

This study uses data drawn from Bureau van Dijk's Orbis database. First, the study collects a sample of Global Ultimate Owners (hereafter GUOs) operating in the industrial sector. A GUO is an entity that controls more than one subsidiary, but is not controlled by any single shareholder. Controlling is defined as greater than $50 \%$ ownership. In the next step, all subsidiaries controlled by GUOs are included in the sample. Financial statement data from unconsolidated financial statements of these GUOs and subsidiaries are obtained for the period from 2008 to 2015. 
A set of a GUO and its controlling subsidiaries represents one MNC group. Because the present study investigates the effects of country characteristics on group-level tax avoidance, financial data of GUOs and their controlling subsidiaries are aggregated to form each group year in this study.

Group years with negative or zero pretax incomes are excluded because pretax income should be greater than zero to calculate worldwide GAAP ETR, which is used to measure the dependent variable, TAXAVOIDANCE. In addition, there may be different tax incentives among losing and profitable multinationals (De Simone et al. [44]). Group years are excluded from the sample if they have missing financial data for variables. Lastly, group years in which the number of subsidiaries belongs to the upper $1 \%$ of that of the overall observations are excluded to control for the effects of outliers. The final sample of group years comprises 36,235 observations domiciled in 31 countries for the years 2008 to 2015 .

The sample obtained from the Orbis data is subject to certain limitations. First, since the Orbis data provide only static ownership information of MNCs for the most recent year, it is impossible to decipher the ownership structure of the MNCs for all years. Therefore, this study is conducted under the assumption that the corporate structures of the MNCs are constant over the analysis period of 2008-2015. Second, GUOs disclosing unconsolidated financial data are solely selected at the first stage of data collection for consistency in financial data. For this reason, most U.S. firm-year observations are excluded from the sample because the Orbis database generally discloses consolidated financial data of U.S. firms only. These limitations of data availability may influence the results of the study to a certain extent. However, the results will not be significantly biased because the corporate structures of MNCs tend to be stable over time, and U.S. GUOs $(3,749)$ account for only $3.82 \%$ of the total GUO observations $(98,252)$ initially collected from the Orbis database.

Table 2 summarizes the sample-selection procedure and statistics for the sample of 36,235 group years. Panel A in Table 2 briefly summarizes the sample-selection procedure; a large number of group years are excluded, due to negative pre-tax income.

Table 2. Sample selection.

\begin{tabular}{|c|c|c|c|c|c|c|c|}
\hline \multicolumn{8}{|c|}{ Panel A: Sample Selection } \\
\hline \multicolumn{7}{|c|}{$\begin{array}{l}\text { Group years of worldwide GUOs in Bureau van Dijk's Orbis database operating in the industrial sector } \\
\text { from } 2008 \text { to } 2015 \text {. }\end{array}$} & 47,619 \\
\hline \multicolumn{7}{|c|}{ Less: Negative pre-tax income } & $(9,595)$ \\
\hline \multicolumn{7}{|c|}{ Less: Missing financial data for variables } & $(1,778)$ \\
\hline \multicolumn{7}{|c|}{ Less: Large number of subsidiaries } & $(11)$ \\
\hline \multicolumn{7}{|c|}{ Total group years used in the estimation } & 36,235 \\
\hline \multicolumn{8}{|c|}{ Panel B: Sample by Parent County } \\
\hline No. & Country & Frequency & Percent & No. & Country & Frequency & Percent \\
\hline 1 & Italy & 5,774 & 15.93 & 17 & Netherlands & 820 & 2.26 \\
\hline 2 & Germany & 3,481 & 9.61 & 18 & Slovakia & 655 & 1.81 \\
\hline 3 & Spain & 3,312 & 9.14 & 19 & Poland & 576 & 1.59 \\
\hline 4 & Japan & 2,987 & 8.24 & 20 & Denmark & 484 & 1.34 \\
\hline 5 & Sweden & 2,791 & 7.70 & 21 & Slovenia & 406 & 1.12 \\
\hline 6 & Belgium & 2,234 & 6.17 & 22 & Greece & 259 & 0.71 \\
\hline 7 & France & 2,098 & 5.79 & 23 & Estonia & 254 & 0.70 \\
\hline 8 & Finland & 1,291 & 3.56 & 24 & Turkey & 241 & 0.67 \\
\hline 9 & Czech Republic & 1,187 & 3.28 & 25 & Australia & 209 & 0.58 \\
\hline 10 & Norway & 1,122 & 3.10 & 26 & Ireland & 149 & 0.41 \\
\hline 11 & Republic of Korea & 1,079 & 2.98 & 27 & Switzerland & 100 & 0.28 \\
\hline 12 & Luxembourg & 955 & 2.64 & 28 & Canada & 92 & 0.25 \\
\hline 13 & Portugal & 942 & 2.60 & 29 & New Zealand & 29 & 0.08 \\
\hline 14 & Austria & 941 & 2.60 & 30 & Mexico & 13 & 0.04 \\
\hline 15 & United States & 891 & 2.46 & 31 & Chile & 3 & 0.01 \\
\hline 16 & Hungary & 860 & 2.37 & & & & \\
\hline Total & & & & & & 36,235 & 100.00 \\
\hline
\end{tabular}


Table 2. Cont.

\begin{tabular}{|c|c|c|c|c|c|c|c|}
\hline \multicolumn{8}{|c|}{ Panel C: Sample by Subsidiary Country } \\
\hline No. & Country & Frequency & Percent & No. & Country & Frequency & Percent \\
\hline 1 & Japan & 20,314 & 12.36 & 39 & Colombia & 391 & 0.24 \\
\hline 2 & Italy & 17,704 & 10.77 & 40 & Philippines & 386 & 0.23 \\
\hline 3 & France & 15,648 & 9.52 & 41 & Malta & 306 & 0.19 \\
\hline 4 & Spain & 11,433 & 6.96 & 42 & Brazil & 272 & 0.17 \\
\hline 5 & Germany & 11,244 & 6.84 & 43 & Ukraine & 200 & 0.12 \\
\hline 6 & Sweden & 8,712 & 5.30 & 44 & Bosnia and Herzegovina & 183 & 0.11 \\
\hline 7 & Belgium & 7,876 & 4.79 & 45 & Thailand & 120 & 0.07 \\
\hline 8 & United Kingdom & 6,400 & 3.89 & 46 & United States & 116 & 0.07 \\
\hline 9 & Poland & 5,320 & 3.24 & 47 & Mexico & 97 & 0.06 \\
\hline 10 & Norway & 5,010 & 3.05 & 48 & Algeria & 94 & 0.06 \\
\hline 11 & Netherlands & 4,732 & 2.88 & 49 & Taiwan & 88 & 0.05 \\
\hline 12 & Czech Republic & 3,866 & 2.35 & 50 & Montenegro & 82 & 0.05 \\
\hline 13 & Portugal & 3,830 & 2.33 & 51 & Peru & 77 & 0.05 \\
\hline 14 & Romania & 3,623 & 2.20 & 52 & Republic of Moldova & 62 & 0.04 \\
\hline 15 & Finland & 3,584 & 2.18 & 53 & Indonesia & 55 & 0.03 \\
\hline 16 & Republic of Korea & 3,463 & 2.11 & 54 & Cyprus & 53 & 0.03 \\
\hline 17 & China & 3,341 & 2.03 & 55 & Macedonia & 46 & 0.03 \\
\hline 18 & Hungary & 2,899 & 1.76 & 56 & Uruguay & 42 & 0.03 \\
\hline 19 & Austria & 2,867 & 1.74 & 57 & Iceland & 29 & 0.02 \\
\hline 20 & Slovakia & 2,594 & 1.58 & 58 & Albania & 27 & 0.02 \\
\hline 21 & Denmark & 2,428 & 1.48 & 59 & South Africa & 19 & 0.01 \\
\hline 22 & Russia & 2,063 & 1.26 & 60 & Chile & 15 & 0.01 \\
\hline 23 & Australia & 1,491 & 0.91 & 61 & Paraguay & 13 & 0.01 \\
\hline 24 & Estonia & 1,458 & 0.89 & 62 & Ecuador & 11 & 0.01 \\
\hline 25 & India & 1,181 & 0.72 & 63 & Argentina & 10 & 0.01 \\
\hline 26 & Greece & 1,058 & 0.64 & 64 & Angola & 6 & 0.00 \\
\hline 27 & Serbia & 841 & 0.51 & 65 & Bolivia & 6 & 0.00 \\
\hline 28 & Luxembourg & 830 & 0.50 & 66 & Switzerland & 5 & 0.00 \\
\hline 29 & Slovenia & 683 & 0.42 & 67 & Gabon & 5 & 0.00 \\
\hline 30 & Turkey & 651 & 0.40 & 68 & Cape Verde & 4 & 0.00 \\
\hline 31 & Ireland & 644 & 0.39 & 69 & Mauritius & 4 & 0.00 \\
\hline 32 & Latvia & 641 & 0.39 & 70 & Cambodia & 3 & 0.00 \\
\hline 33 & Morocco & 588 & 0.36 & 71 & Pakistan & 3 & 0.00 \\
\hline 34 & Croatia & 552 & 0.34 & 72 & Saudi Arabia & 2 & 0.00 \\
\hline 35 & Bulgaria & 531 & 0.32 & 73 & Israel & 1 & 0.00 \\
\hline 36 & Lithuania & 504 & 0.31 & 74 & Sri Lanka & 1 & 0.00 \\
\hline 37 & Singapore & 489 & 0.30 & 75 & Nigeria & 1 & 0.00 \\
\hline 38 & New Zealand & 454 & 0.28 & & & & \\
\hline Total & & & & & & 164,382 & 100.00 \\
\hline \multicolumn{8}{|c|}{ Panel D: Sample by Year } \\
\hline Year & Frequency & \multicolumn{2}{|c|}{ Percent } & Year & \multicolumn{2}{|l|}{ Frequency } & Percent \\
\hline 2008 & 4051 & \multicolumn{2}{|c|}{11.18} & 2012 & \multicolumn{2}{|l|}{4626} & 12.77 \\
\hline 2009 & 3969 & \multicolumn{2}{|c|}{10.95} & 2013 & \multicolumn{2}{|l|}{4739} & 13.08 \\
\hline 2010 & 4408 & \multicolumn{2}{|c|}{12.17} & 2014 & \multicolumn{2}{|l|}{4937} & 13.62 \\
\hline 2011 & 4532 & \multicolumn{2}{|c|}{12.51} & 2015 & \multicolumn{2}{|l|}{4973} & 13.72 \\
\hline Total & & & & & \multicolumn{2}{|l|}{36,235} & 100 \\
\hline \multicolumn{8}{|c|}{ Panel E: Sample by Industry } \\
\hline \multicolumn{5}{|c|}{ Industry by SIC Code } & \multicolumn{2}{|l|}{ Frequency } & Percent \\
\hline & & & & & 12,577 & & 34.69 \\
\hline & Manı & turing & & & 10,696 & & 29.50 \\
\hline & Transportation & public utiliti & & & 8265 & & 22.80 \\
\hline & Agriculture & estry, fishing & & & 1917 & & 5.29 \\
\hline & Wholesa & etail trade & & & 1658 & & 4.57 \\
\hline & Con & ction & & & 758 & & 2.09 \\
\hline & Public a & nistration & & & 364 & & 1.00 \\
\hline Total & & & & & 36,235 & & 100 \\
\hline
\end{tabular}


Panel B in Table 2 shows the sample distribution by parent (i.e., GUO) country. Parent companies are established in 31 countries. The country with the largest number of parent-year observations is Italy (15.93\%), followed by Germany (9.61\%), Spain (9.14\%), and Japan (8.24\%). Parents located in the U.S. are generally excluded from the sample because unconsolidated financial information of those U.S. parents is not disclosed in the Orbis database.

Panel C in Table 2 reports the sample distribution by subsidiary country. Subsidiaries are located in 75 countries. The financial data of subsidiaries are aggregated with their parents to form group-year observations. It is important to understand the subsidiary sample distribution because certain variables (e.g., average tax rates of subsidiary countries, average Hofstede's dimension scores of subsidiary countries) are calculated based on the financial and country data of the subsidiaries.

Panel $\mathrm{D}$ in Table 2 reports the sample distribution by year. The number of affiliate-year observations generally increases by the year. Lastly, Panel E in Table 2 shows the sample by industry classified according to SIC Code. Of the parent-year observations, 34.69\% are engaged in the service industry.

\subsection{Research Model}

To test the influence of national culture on tax avoidance by MNCs, the following equations are estimated using the pooled ordinary least squares (OLS) method.

TAXAVOIDANCE

$$
\begin{aligned}
& =\beta_{0}+\beta_{1} \text { TAX }_{i t}+\beta_{2} P_{-} \text {CULTURE }_{i t}+\beta_{3} \text { CONTROLS }_{i t}+\Sigma Y \text { EARfe } \\
& +\Sigma I N D f e+\Sigma \text { COUNTRYfe }+\varepsilon_{i t},
\end{aligned}
$$

TAXAVOIDANCE $E_{i t}$

$$
\begin{aligned}
& =\beta_{0}+\beta_{1} \text { TAX }_{i t}+\beta_{2} S_{-} \text {CULTURE }_{i t}+\beta_{3} \text { CONTROLS }_{i t}+\Sigma Y \text { YARfe } \\
& +\Sigma I N D f e+\Sigma \text { COUNTRYfe }+\varepsilon_{i t},
\end{aligned}
$$

TAXAVOIDANCE $E_{i t}$

$$
\begin{aligned}
& =\beta_{0}+\beta_{1} T_{A A X}+\beta_{2} P_{-}{ }_{C H L T U R E}+\beta_{3} S_{-} \text {CULTURE }_{i t} \\
& +\beta_{4} \text { CONTROLS }_{i t}+\Sigma Y \text { YARfe }+\Sigma I N D f e+\Sigma C O U N T R Y f e+\varepsilon_{i t},
\end{aligned}
$$

where, TAXAVOIDANCE is the worldwide GAAP ETR (WW_GETR) of the group multiplied by negative one, calculated according to the following equation:

$$
\begin{aligned}
\text { TAXAVOIDANCE }= & \text { Worldwide_GAAP_ETR } \times(-1), \\
& \text { Worldwide_GAAP_ETR }=\frac{G U O_{-} T A X_{k}+\sum_{j=1}^{n} S U B_{-} T A X_{j}}{G U O_{-} P B T_{k}+\sum_{j=1}^{n} S U B_{-} P L B T_{j}}
\end{aligned}
$$

where GUO_TAX $X_{k}$ is the income taxes of parent $k$ of the group, GUO_PLBT $k$ is the pre-tax income of parent $k$ of the group, $S U B_{-} T A X_{j}$ is the income taxes of subsidiary $j, S U B_{-} P L B T_{j}$ is the pre-tax income of subsidiary $j$ (where $j$ runs from 1 to $\mathrm{n}$ and $\mathrm{n}$ is the number of subsidiaries controlled by parent $k)$; TAX is an indicator variable for tax incentives equaling 1 if the average statutory tax rate of the subsidiaries is lower than the statutory tax rate of the parent of the group and 0 otherwise. Specifically, $T A X$ is calculated according to the following equation:

$$
\begin{aligned}
T A X= & 1 \text { if } A V G \_S U B \_S T R_{k}-G U O \_S T R_{k}<0, \\
T A X= & 0 \text { if } A V G \_S U B \_S T R_{k}-G U O \_S T R_{k} \geq 0, \\
& A V G \_S U B \_S T R_{k}=\frac{\sum_{j=1}^{n} S U B_{-} S T R_{j}}{n}
\end{aligned}
$$

where $S U B \_S T R_{j}$ is the statutory tax rate of subsidiary $j$ (where $j$ runs from 1 to $\mathrm{n}$ and $\mathrm{n}$ is the number of subsidiaries controlled by parent $k$ ), AVG_SUB_STR $k$ is the average statutory tax rate of subsidiaries controlled by parent $k$, GUO_STR $R_{j}$ is the statutory tax rate of $G U O_{k}$ of the group; P_CULTURE is 
Hofstede's cultural-dimension-index scores of the home country of the parent of the group (i.e., $P \_U A I$, $P \_I D V, P \_M A S$, and $\left.P_{-} P D I\right) ; S_{-} C U L T U R E$ is the average cultural-dimension-index scores of the home countries of the subsidiaries of the group (i.e., $S \_U A I, S \_I D V, S \_M A S$, and $S \_P D I$ ), which is calculated according to the following equation:

$$
S_{-} C U L T U R E=\frac{\sum_{j=1}^{n} S U B_{-} C U L T U R E_{j}}{n}
$$

where SUB_CULTUREj is each cultural dimension index (UAI, IDV, MAS, and PDI) of the home countries of the subsidiary $j$ (where $j$ runs from 1 to $n$ and $n$ is the number of subsidiaries controlled by parent $k$ ); N_SUB is the natural logarithm of the number of subsidiaries of the group plus one; SIZE is the natural logarithm of the total assets (in thousands of US dollars) of the group; ROA is the ratio of the group's pre-tax income to the group's total assets in the previous year; INT is the ratio of the group's intangibles to the group's total assets in the previous year; SALESGR is the ratio of the group's sales to the group's sales in the previous year minus one; GDP is the natural logarithm of the per-capita nominal GDP (in millions of US dollars) of the home country of the parent of the group; TRADE is the natural logarithm of the amount of trade (in millions of USD) of the home country of the parent of the group; DUM_LAW is an indicator variable equaling 1 if the home country of the parent of the group adopts civil law and 0 if it adopts common law.

To supplement the problems with any unobservable heterogeneity across corporate groups, this study includes year, industry, and country fixed effects in the OLS regression model. All continuous variables are winsorized at the 1st and 99th percentiles to mitigate the effects of outliers. This paper follows Petersen [45] by calculating robust-standard errors clustered by MNC groups (Atwood et al. [46]; Atwood and Lewellen [47]) to alleviate time-series dependence.

Three equations estimate the effects of tax (i.e., tax rate difference) and cultural features on tax avoidance by MNCs. Equation (1) focuses on the effects of the parent country's culture on tax avoidance. This equation is established based on the premise that the parent of the group is the most influential subject who makes final decisions for aggressive tax planning. The four hypotheses of this study are tested by estimating Equation (1).

The purpose of Equation (2) is to further examine the effects of the subsidiary countries' cultures on tax-avoidance decisions. In addition, Equation (3) investigates the effects of both the parent and subsidiary countries' cultures in a combined manner. The following section provides a detailed explanation of the variables employed in the research model.

\subsubsection{Dependent Variable}

In the previous literature, various measures of tax avoidance are used to estimate the level of corporate tax avoidance. In this study, the measure TAXAVOIDANCE, which is calculated as the worldwide GAAP ETR multiplied by negative one, is used as a proxy for tax avoidance to broadly capture MNCs' tax-avoidance behavior.

ETR implies different inferences depending on the factors used in the denominator and the numerator. In general, the literature on tax avoidance uses GAAP ETR or cash ETR to measure the level of corporate tax avoidance. The former is the ratio of total income tax expenses to total pre-tax accounting income, while the latter is the ratio of cash taxes paid to total pre-tax accounting income (Gupta and Newberry [48]; Robinson et al. [49]; Hanlon and Heitzman [50]). In this study, GAAP ETR is used as a dependent variable because it is difficult to obtain the actual amount of cash taxes paid by parents and subsidiaries in MNCs across countries.

Because this study investigates the effects of culture on group-level tax avoidance, worldwide GAAP ETR is used instead of firm-level GAAP ETR. Worldwide GAAP ETR is calculated as the ratio of the group's aggregated total income tax expenses of the parent and subsidiary companies to the aggregated total pre-tax earnings of the parent and subsidiary companies. 
A lower level of GAAP ETR indicates a lower level of income taxes, and a consequently higher level of tax avoidance. For ease of interpretation, TAXAVOIDANCE multiplies worldwide GAAP ETR by negative one so that the lower (higher) level of GAAP ETR leads to higher (lower) level of TAXAVOIDANCE.

Some studies use the long-run ETR based on the consideration of the long-run nature of corporate tax avoidance. Dyreng et al. [51] propose using a long-run cash ETR (the ratio of total cash taxes paid over ten years to total pre-tax earnings over the same period) to avoid a mismatch of cash taxes and earnings. The present study, however, uses a single-year worldwide GAAP ETR instead of long-run worldwide GAAP ETR for the following reasons.

First, to calculate the long-run GAAP ETR, there should be no missing financial data of the sample observations for a minimum of five to ten years. Unfortunately, the sample period of this study is relatively short, 2008-2015, and a number of sample groups have missing values during this period. Second, because the long-run measure estimates GAAP ETR for an overlapping period, the results may suffer from intra-firm correlation, and consequently, a time-series dependency problem (Petersen [45]; Mills et al. [52]). Nevertheless, the analysis using this long-run worldwide ETR is also conducted in the robustness test to examine the effects of culture on MNCs' long-term tax planning.

In summary, this study measures the level of tax avoidance using the measure TAXAVOIDANCE, which is calculated as the worldwide GAAP ETR of MNCs multiplied by negative one. Any group years with negative pre-tax income are excluded from the final sample observations because GAAP ETR cannot be estimated. Also, worldwide GAAP ETR is adjusted to range from zero to one, consistent with previous literature (e.g., Gupta and Newberry [48]; Robinson et al. [49]).

\subsubsection{Independent Variable}

The main purpose of this study is to identify the cultural effects on tax avoidance. However, tax incentives are undoubtedly one of the most significant and influential factors determining the tax-avoidance behaviors of MNCs. A number of prior studies find evidence that tax-rate differences between affiliates motivate MNCs to engage in tax planning by shifting income across countries (e.g., Klassen et al. [53]; Hines and Rice [54]; Jacob [55]; Collins et al. [56]; Mills and Newberry [57]; Clausing [58]; Huizinga and Laeven [59]; Klassen and Laplante [60]; Klassen and Laplante [60]). Therefore, this study also employs a tax variable (TAX) to capture the impact of tax incentives on avoidance. TAX is an indicator equaling 1 if the average tax rate of the subsidiaries (AVG_SUB_STR) is lower than the tax rate of the parent (GUO_STR) of each respective group. The average tax rate of the subsidiaries is calculated by dividing the aggregated tax rates of subsidiary countries by the number of subsidiaries residing in the respective countries. Because greater tax-rate differences across affiliates provide MNCs more opportunities for tax avoidance by strategically shifting income to lower-tax-rate jurisdictions to reduce the worldwide tax burden, the coefficient on TAX is predicted to be greater than zero.

The key independent variables in the present study are Hofstede's cultural dimensions. The scores of the four dimension of parent countries ( $\left.P_{-} C U L T U R E\right)$ are used to test the hypotheses. This study predicts that $P_{-} U A I, P_{-} I N D$, and $P_{-} P D I$ negatively affects tax avoidance by MNCs. Therefore, the coefficients on the scores of the three dimensions are expected to be negative. On the contrary, the study expects a positive relationship between $P_{-} M A S$ and tax avoidance of MNCs. Thus, the coefficient on $P_{-}$MAS is expected to be positive.

Equations (2) and (3) further investigate the role of the subsidiary countries' cultures in tax avoidance by MNCs. In Equation (2), Hofstede's dimension scores of the parent countries (P_CULTURE) are replaced by those of the subsidiary countries (S_CULTURE). Hofstede's dimension scores of both P_CULTURE and S_CULTURE are included in Equation (3) to capture the combined effects of national culture. Because the effects of subsidiary countries' cultures on tax avoidance are not predictable, this study does not predict coefficient signs for $S_{-} U A I, S \_I D V, S \_M A S$, and $P \_P D I$. 


\subsubsection{Control Variables}

The present study includes control variables used in prior studies to capture other factors affecting tax avoidance by MNCs. Firms have incentives to reduce their taxes by strategically shifting income to lower-tax-rate jurisdictions using transfer pricing or any other means (e.g., Merks et al. [61]; Heckemeyer and Overesch [62]; Clausing [58]; Davies et al. [63]; Cristea and Nguyen [64]). The empirical model in this study contains the natural logarithm of the number of subsidiaries of an MNC (N_SUB) based on the prediction that MNCs with a greater number of affiliates have more opportunities for tax planning and avoidance. The coefficient on N_SUB is expected to be significantly positive.

To control for economies of scale and any political costs arising from the size of MNCs, the natural logarithm of the total assets (SIZE) is included in the empirical model. Considering the inconsistent evidence in prior studies (e.g., Gupta and Newberry [48]), the coefficient sign of SIZE is not predicted. The profitability of MNCs is controlled using return on assets $(R O A)$. Due to inconsistent evidence found by prior studies on profitability and tax avoidance (Mills et al. [52]; Koh et al. [65]), the coefficient sign of $R O A$ is also not predicted.

The ratio of intangibles to total assets in the previous year (INT) is controlled. Desai and Hines [66] highlight firms' incentives to shift income to lower-tax-rate jurisdictions by exploiting intangibles. Accordingly, the coefficient on INT is predicted to be greater than zero. Chen et al. [67] find that fast-growing firms tend to invest more in tax-favored assets compared with other firms. This study includes a control variable, the sales growth ratio (SALESGR), to control for the future growth potential of MNCs. The coefficient sign is predicted to be positive. Because the economic magnitude of parent countries may influence the level of MNCs' tax avoidance, the natural logarithm of GDP (GDP), and the amount of trade (TRADE) of parent countries are included in the empirical model. N_SUB, SIZE, GDP and TRADE are transformed to logarithmic value to secure normality by mitigating the overwhelming effects of observations with high raw values. This study predicts that GDP and TRADE are negatively related to tax avoidance, consistent with prior studies (e.g., Tsakumis et al. [6]). Lastly, a variable for legal systems (DUM_LAW) is included to control for any features arising from the difference between the social and common law systems, according to La Porta et al. [68]. Consistent with the predictions of Richardson [8] and Bame-Aldred et al. [9], this study predicts that MNCs in countries adopting the civil law system is likely to engage in tax avoidance to a lesser extent because civil law system relies more on written statutes and other legal codes. Therefore, the coefficient on DUM_LAW is expected to be negative.

In addition to the aforementioned control variables, year, industry, and country fixed effects are controlled to capture the effects of heterogeneity across groups and countries.

\section{Results}

\subsection{Descriptive Statistics and Correlation Analysis}

Panel A in Table 3 presents the summary statistics for the variables during the period 2008-2015. The final sample comprises 36,235 group-year observations. The mean value of TAXAVOIDANCE is -0.27 , indicating that global MNCs paid $27 \%$ of their earnings as income taxes on average. This estimation is slightly higher than the average statutory tax rates of the 31 sample countries for 2008-2015 (25.6\%). The mean value of TAX is 0.66 , which implies that subsidiaries are headquartered in lower-tax-rate jurisdictions than their parent companies in $66 \%$ of the total group years in this sample.

The mean values of Hofstede's cultural dimensions for parent (P_CULTURE), and subsidiary (S_CULTURE) countries are also reported. Except for the PDI score, the scores of the cultural dimensions are, on average, higher for parent countries than for subsidiary countries. In general, Hofstede's dimension scores differ significantly between parent countries and subsidiary countries.

Panel B in Table 3 reports the means of the main variables grouped by parent country. MNCs headquartered in Italy (44\%), and Estonia (11\%) have the lowest and highest mean values of TAXAVOIDANCE, respectively. The difference between the average statutory tax rates of subsidiary 
countries and the statutory tax rate of the parent country indicates the tax incentives of MNCs to engage in tax planning to reduce their worldwide tax burden. The US has the highest incentive for tax planning $(\mathrm{DIFF}=13 \%)$, followed by Japan $(\mathrm{DIFF}=12 \%)$, because both countries have high statutory corporate tax rates.

To examine whether MNCs with different tax features show differences in cultural dimensions, the mean values of the main variables are compared between MNCs whose subsidiaries are located in jurisdictions with lower tax rates than the parent countries (low-tax-rate subsidiary MNCs, TAX =1), and MNCs whose subsidiaries are located in jurisdictions with higher tax rates than the parent countries (high-tax-rate subsidiary MNCs, TAX =0). Table 4 reports the results of the t-test. TAXAVOIDANCE is $2 \%$ lower for low-tax-rate subsidiary MNCs than for high-tax-rate subsidiary MNCs at a significance level of $1 \%$. The cultural dimension scores of the parent countries (P_CULTURE) are also significantly higher for low-tax-rate subsidiary MNCs than for high-tax-rate subsidiary MNCs at $1 \%$. On the contrary, the cultural dimension scores of subsidiary countries (S_CULTURE) are generally lower for low-tax-rate subsidiary MNCs than for high-tax-rate subsidiary MNCs. These results highlight the need to examine the effects of both parent and subsidiary cultures on tax avoidance.

Table 5 shows the correlations of the variables. The dependent variable (TAXAVOIDANCE) generally has significant correlations with the independent variables, except for $P \_P D I$. The signs of the correlation coefficients on TAX and certain control variables are inconsistent with the predictions. Because these correlation coefficients are estimated without controlling the effects of confounding factors, the relationships are investigated using multivariate regression in the next section. 
Table 3. Descriptive statistics.

\begin{tabular}{|c|c|c|c|c|c|c|c|c|c|c|c|c|}
\hline \multicolumn{13}{|c|}{ Panel A: Summary Statistics for the Variables } \\
\hline No & Variables & $\mathbf{N}$ & \multicolumn{2}{|r|}{ Mean } & \multicolumn{2}{|c|}{ Median } & \multicolumn{2}{|c|}{ SD } & \multicolumn{2}{|c|}{ Min } & \multicolumn{2}{|c|}{ Max } \\
\hline 1 & TAX AVOIDANCE & 36,235 & \multicolumn{2}{|r|}{-0.27} & \multicolumn{2}{|c|}{-0.23} & \multicolumn{2}{|c|}{0.22} & \multicolumn{2}{|c|}{-1.00} & \multicolumn{2}{|c|}{0.00} \\
\hline 2 & TAX & 36,235 & \multicolumn{2}{|r|}{0.66} & 1. & & \multicolumn{2}{|c|}{0.48} & \multicolumn{2}{|c|}{0.00} & \multicolumn{2}{|c|}{1.00} \\
\hline 3 & P_UAI & 36,235 & \multicolumn{2}{|r|}{72.20} & 75 & & \multicolumn{2}{|c|}{19.58} & \multicolumn{2}{|c|}{29.00} & \multicolumn{2}{|c|}{104.00} \\
\hline 4 & P_IDV & 36,235 & \multicolumn{2}{|r|}{63.05} & 67 & & \multicolumn{2}{|c|}{15.75} & \multicolumn{2}{|c|}{18.00} & \multicolumn{2}{|c|}{91.00} \\
\hline 5 & P_MAS & 36,235 & \multicolumn{2}{|r|}{53.06} & 54 & & \multicolumn{2}{|c|}{26.29} & \multicolumn{2}{|c|}{5.00} & 110 & \\
\hline 6 & $P_{-} P D I$ & 36,235 & & 48.93 & 50 & & 15 & & 18 & & 10 & .00 \\
\hline 7 & S_UAI & 36,235 & & 65.70 & 70 & & 24 & & 0. & & 10 & .00 \\
\hline 8 & $S \_I D V$ & 36,235 & & 50.02 & 53 & & 20 & & 0. & & 91 & 00 \\
\hline 9 & $S \_M A S$ & 36,235 & & 45.58 & 43 & & 23 & & 0. & & 110 & .00 \\
\hline 10 & $S \_P D I$ & 36,235 & & 55.52 & 57 & & 23 & & 0. & & 10 & .00 \\
\hline 11 & N_SUB & 36,235 & & 1.14 & 0. & & 0. & & 0. & & 3. & 83 \\
\hline 12 & $\overline{S I Z E}$ & 36,235 & & 10.84 & 10 & & 1. & & 5. & & 19 & 76 \\
\hline 13 & $R O A$ & 36,235 & & 0.11 & 0. & & 0. & & 0. & & 1. & 22 \\
\hline 14 & $I N T$ & 36,235 & & 0.03 & 0 . & & 0. & & 0. & & 0. & 62 \\
\hline 15 & SALESGR & 36,235 & & 0.36 & 0. & & 1. & & -0 & & 19 & 16 \\
\hline 16 & GDP & 36,235 & & 10.55 & 10 & & 0. & & 9. & & 11 & 54 \\
\hline 17 & $T R A D E$ & 36,235 & & 4.12 & 4. & & 0. & & 2. & & 5. & 20 \\
\hline 18 & DUM_LAW & 36,235 & & 0.96 & 1. & & 0 . & & 0. & & 1. & 00 \\
\hline & & Panel & : Means of the & e Main Variables & rouped $b$ & Parent & ountry & & & & & \\
\hline Country & $T A X-$ & $A V G_{-} S U B_{-}$ & GUO $\operatorname{STR}(B)$ & DIFF $(A-B)$ & & $P_{-} C U$ & TURE & & & S_CU & TURE & \\
\hline & AVOIDANCE & $\begin{array}{l}S T R \\
(A)\end{array}$ & & & $P_{-} U A I$ & $P_{-} I N D$ & $P \_M A S$ & $P_{-} P D I$ & S_UAI & S_IND & S_MAS & S_PDI \\
\hline Italy & -0.44 & 0.25 & 0.31 & -0.06 & 75 & 76 & 70 & 50 & 71.39 & 46.83 & 46.81 & 61.01 \\
\hline Germany & -0.26 & 0.24 & 0.30 & -0.06 & 65 & 67 & 66 & 35 & 70.84 & 54.96 & 52.84 & 52.16 \\
\hline Spain & -0.23 & 0.27 & 0.30 & -0.03 & 86 & 51 & 42 & 57 & 79.4 & 42.37 & 44.54 & 59.89 \\
\hline Japan & -0.32 & 0.26 & 0.38 & -0.12 & 92 & 46 & 95 & 54 & 49.89 & 34.36 & 48.46 & 61.21 \\
\hline Sweden & -0.22 & 0.25 & 0.25 & 0.00 & 29 & 71 & 5 & 31 & 56.31 & 59.01 & 28.31 & 39.35 \\
\hline Belgium & -0.23 & 0.28 & 0.34 & -0.06 & 94 & 75 & 54 & 65 & 72.08 & 62.43 & 44.75 & 57.67 \\
\hline France & -0.20 & 0.27 & 0.33 & -0.06 & 86 & 71 & 43 & 68 & 70.01 & 49.18 & 45.71 & 52.84 \\
\hline Finland & -0.21 & 0.23 & 0.24 & -0.01 & 59 & 63 & 26 & 33 & 54.21 & 59.66 & 25.23 & 44.28 \\
\hline Czech Republic & -0.22 & 0.21 & 0.19 & 0.02 & 74 & 58 & 57 & 57 & 62.66 & 52.42 & 90.03 & 90.02 \\
\hline Norway & -0.24 & 0.24 & 0.28 & -0.04 & 50 & 69 & 8 & 31 & 39.42 & 60.95 & 18.65 & 33.66 \\
\hline
\end{tabular}


Table 3. Cont.

\begin{tabular}{|c|c|c|c|c|c|c|c|c|c|c|c|c|}
\hline Republic of Korea & -0.22 & 0.26 & 0.25 & 0.01 & 85 & 18 & 39 & 60 & 55.16 & 42.99 & 57.76 & 65.79 \\
\hline Luxembourg & -0.24 & 0.29 & 0.29 & 0.00 & 70 & 60 & 50 & 40 & 76.41 & 64.61 & 51.8 & 55.12 \\
\hline Portugal & -0.22 & 0.30 & 0.24 & 0.06 & 104 & 27 & 31 & 63 & 74.44 & 47.6 & 43.11 & 57.11 \\
\hline Austria & -0.22 & 0.23 & 0.25 & -0.02 & 70 & 55 & 79 & 11 & 71.2 & 57.32 & 62.21 & 54.44 \\
\hline United States & -0.25 & 0.27 & 0.40 & -0.13 & 46 & 91 & 62 & 40 & 46.28 & 45.1 & 36.52 & 36.95 \\
\hline Hungary & -0.14 & 0.18 & 0.18 & 0.00 & 82 & 80 & 88 & 46 & 82.6 & 38.61 & 51.33 & 78.44 \\
\hline Netherlands & -0.26 & 0.27 & 0.25 & 0.02 & 53 & 80 & 14 & 38 & 72.33 & 56.69 & 48.97 & 53.42 \\
\hline Slovakia & -0.22 & 0.20 & 0.20 & 0.00 & 51 & 52 & 110 & 104 & 75.76 & 54.11 & 55.83 & 57.72 \\
\hline Poland & -0.22 & 0.23 & 0.19 & 0.04 & 93 & 60 & 64 & 68 & 68.79 & 56.36 & 50.54 & 54.89 \\
\hline Denmark & -0.20 & 0.25 & 0.24 & 0.01 & 23 & 74 & 16 & 18 & 52.09 & 55.75 & 29.84 & 40.6 \\
\hline Slovenia & -0.18 & 0.17 & 0.19 & -0.02 & 88 & 27 & 19 & 71 & 70.81 & 29.69 & 38.59 & 62.94 \\
\hline Greece & -0.28 & 0.18 & 0.24 & -0.06 & 112 & 35 & 57 & 60 & 63.73 & 30.75 & 35.75 & 55.82 \\
\hline Estonia & -0.11 & 0.19 & 0.21 & -0.02 & 60 & 60 & 30 & 40 & 66.72 & 59.51 & 22.97 & 48.76 \\
\hline Turkey & -0.19 & 0.23 & 0.20 & 0.03 & 85 & 37 & 45 & 66 & 65.14 & 49.57 & 41.3 & 48.92 \\
\hline Australia & -0.23 & 0.26 & 0.30 & -0.04 & 51 & 90 & 61 & 38 & 33.58 & 42.95 & 38.45 & 31.54 \\
\hline Ireland & -0.22 & 0.25 & 0.13 & 0.12 & 35 & 70 & 68 & 28 & 24.51 & 21.86 & 18.23 & 18.05 \\
\hline Switzerland & -0.26 & 0.27 & 0.18 & 0.09 & 58 & 68 & 70 & 34 & 61.46 & 56.47 & 54.29 & 46.27 \\
\hline Canada & -0.24 & 0.27 & 0.28 & -0.01 & 48 & 80 & 52 & 39 & 43.32 & 43.15 & 35.19 & 38.86 \\
\hline New Zealand & -0.16 & 0.27 & 0.29 & -0.02 & 49 & 79 & 58 & 22 & 42.72 & 53.8 & 42.51 & 33.66 \\
\hline Mexico & -0.24 & 0.29 & 0.30 & -0.01 & 82 & 30 & 69 & 81 & 78 & 45.79 & 45.52 & 57.62 \\
\hline Chile & -0.33 & 0.32 & 0.17 & 0.15 & 86 & 23 & 28 & 63 & 81.1 & 27.19 & 51.24 & 63.19 \\
\hline Total & -0.27 & 0.25 & 0.29 & -0.04 & 72.17 & 63.05 & 53.06 & 48.75 & 65.72 & 50.02 & 45.58 & 55.52 \\
\hline
\end{tabular}

(1) Panel A reports the summary statistics for the final sample of group years; (2) Panel B reports the means of the main variables grouped by parent country; (3) TAXAVOIDANCE is the worldwide GAAP ETR multiplied by negative one; TAX is an indicator variable for tax incentives equaling 1 if the average tax rate of the subsidiaries is lower than the tax rate of the parent of the group, and 0 otherwise; $P_{-} U A I, P_{-} I D V, P_{-} M A S$, and $P_{-} P D I$ are Hofstede's cultural-dimension-index scores of the home country of the parent of the group; $S_{-} U A I, S_{-} I D V, S_{-} M A S$, and $S \_P D I$ are the average cultural-dimension-index scores of the home countries of the subsidiaries of the group; $N \_S U B$ the natural logarithm of the number of subsidiaries of the group plus one; SIZE is the natural logarithm of the total assets of the group; ROA is the ratio of the group's pre-tax income to group i's total assets in the previous year; INT is the ratio of the group's intangibles to the group's total assets in the previous year; SALESGR is the ratio of the group's sales to the group's sales in the previous year minus one; GDP is the natural logarithm of the per-capita GDP of the home country of the parent of the group; TRADE is the natural logarithm of the amount of trade of the home country of the parent of the group.; DUM_LAW is an indicator variable equaling 1 if the home country of the parent of the group adopts civil law and 0 if it adopts common law; (4) AVG_SUB_STR is the average statutory tax rates of the subsidiaries of the group; GUO_STR is the statutory tax rates of the parent companies. 
Table 4. T-test results.

\begin{tabular}{ccccc}
\hline Variable & $\begin{array}{c}\text { Low-tax-rate } \\
\text { Subsidiary MNCs } \\
\text { TAX } \mathbf{X} \mathbf{1} \text { (A) }\end{array}$ & $\begin{array}{c}\text { High-tax-rate } \\
\text { Subsidiary MNCs } \\
\text { TAX }=\mathbf{0} \text { (B) }\end{array}$ & DIFF (A-B) & T-stat \\
\hline TAX AVOIDANCE & -0.27 & -0.25 & -0.02 & $-9.72^{* * *}$ \\
P_UAI & 73.97 & 68.82 & 5.14 & $23.95^{* * *}$ \\
P_IDV & 65.08 & 59.20 & 5.88 & $34.31^{* * *}$ \\
P_MAS & 57.26 & 45.06 & 12.20 & $43.03^{* * *}$ \\
P_PDI & 49.35 & 48.13 & 1.23 & $7.20^{* * *}$ \\
S_UAI & 65.41 & 66.26 & -0.85 & $-3.09^{* * *}$ \\
S_IDV & 46.48 & 56.76 & -10.28 & $-46.03^{* * *}$ \\
S_MAS & 44.18 & 48.26 & -4.08 & $-15.88^{* * *}$ \\
S_PDI & 55.74 & 55.11 & 0.63 & $2.40^{* *}$ \\
N_SUB & 1.19 & 1.04 & 0.16 & $20.21^{* * *}$ \\
SIZE & 10.96 & 10.60 & 0.36 & $18.00^{* * *}$ \\
ROA & 0.10 & 0.11 & -0.01 & $-4.50^{* * *}$ \\
INT & 0.03 & 0.03 & 0.00 & $-1.58^{* * * *}$ \\
SALESGR & 0.40 & 0.29 & 0.11 & $5.64^{* * *}$ \\
GDP & 10.60 & 10.45 & 0.15 & $31.36^{* * *}$ \\
TRADE & 4.05 & 4.26 & -0.21 & $-37.64^{* * *}$ \\
DUM_LAW & 0.95 & 0.98 & -0.02 & $-13.93^{* * *}$ \\
\hline
\end{tabular}

(1) *** indicates statistical significance at the 1 percent level; (2) TAX is an indicator variable for tax incentives equaling 1 if the average tax rate of the subsidiaries is lower than the tax rate of the parent of the group, and 0 otherwise. Low-tax-rate (high-tax-rate) subsidiary MNCs with $T A X=1(T A X=0)$ are those whose average tax rate of subsidiary countries is lower (higher) than the tax rate of the parent country; (3) TAXAVOIDANCE is the worldwide GAAP ETR multiplied by negative one; $P_{-} U A I, P_{-} I D V, P_{-} M A S$, and $P_{-} P D I$ are Hofstede's cultural-dimension-index scores of the home country of the parent of the group; S_UAI, S_IDV, S_MAS, and S_PDI are the average cultural-dimension-index scores of the home countries of the subsidiaries of the group; $N \_S U B$ the natural logarithm of the number of subsidiaries of the group plus one; SIZE is the natural logarithm of the total assets of the group; ROA is the ratio of the group's pre-tax income to group $i$ 's total assets in the previous year; INT is the ratio of the group's intangibles to the group's total assets in the previous year; SALESGR is the ratio of the group's sales to the group's sales in the previous year minus one; GDP is the natural logarithm of the per-capita GDP of the home country of the parent of the group; TRADE is the natural logarithm of the amount of trade of the home country of the parent of the group.; DUM $\_L A W$ is an indicator variable equaling 1 if the home country of the parent of the group adopts civil law and 0 if it adopts common law. 
Table 5. Correlation matrix.

\begin{tabular}{|c|c|c|c|c|c|c|c|c|c|c|c|c|c|c|c|c|c|c|}
\hline Variables & (1) & (2) & (3) & (4) & (5) & (6) & (7) & (8) & (9) & (10) & (11) & (12) & (13) & (14) & (15) & (16) & (17) & (18) \\
\hline (1) TAXAVOIDANCE & 1.000 & & & & & & & & & & & & & & & & & \\
\hline (2) $T A X$ & -0.051 & 1.000 & & & & & & & & & & & & & & & & \\
\hline (3) $P \_U A I$ & -0.046 & 0.125 & 1.000 & & & & & & & & & & & & & & & \\
\hline (4) $P \_I D V$ & -0.096 & 0.177 & -0.454 & 1.000 & & & & & & & & & & & & & & \\
\hline (5) $P_{-}^{-} M A S$ & -0.157 & 0.221 & -0.025 & 0.466 & 1.000 & & & & & & & & & & & & & \\
\hline (6) $P \_P D I$ & -0.002 & 0.038 & -0.332 & 0.635 & 0.322 & 1.000 & & & & & & & & & & & & \\
\hline (7) $S \_U A I$ & -0.018 & -0.016 & 0.010 & 0.187 & 0.078 & 0.159 & 1.000 & & & & & & & & & & & \\
\hline (8) S_IDV & 0.022 & -0.235 & 0.168 & -0.198 & -0.196 & -0.139 & 0.286 & 1.000 & & & & & & & & & & \\
\hline (9) $S \_M A S$ & -0.036 & -0.083 & -0.116 & 0.227 & 0.295 & 0.170 & 0.268 & 0.370 & 1.000 & & & & & & & & & \\
\hline (10) $S_{-} P D I$ & -0.037 & 0.013 & -0.138 & 0.298 & 0.236 & 0.228 & -0.049 & 0.597 & 0.536 & 1.000 & & & & & & & & \\
\hline (11) N_SUB & 0.025 & 0.106 & 0.097 & -0.072 & 0.065 & -0.093 & -0.018 & -0.131 & -0.053 & -0.103 & 1.000 & & & & & & & \\
\hline (12) SIZE & 0.004 & 0.094 & -0.105 & 0.150 & 0.163 & 0.022 & -0.041 & -0.117 & 0.001 & -0.086 & 0.447 & 1.000 & & & & & & \\
\hline (13) $R O A$ & 0.157 & -0.024 & -0.003 & -0.108 & -0.047 & -0.063 & 0.011 & -0.078 & -0.053 & -0.058 & -0.018 & -0.107 & 1.000 & & & & & \\
\hline (14) INT & -0.029 & 0.008 & 0.015 & 0.004 & -0.023 & 0.002 & -0.002 & -0.016 & -0.039 & -0.039 & 0.039 & 0.049 & 0.189 & 1.000 & & & & \\
\hline (15) SALESGR & 0.007 & 0.030 & -0.045 & 0.016 & 0.071 & -0.015 & -0.033 & -0.034 & 0.014 & 0.006 & 0.004 & 0.029 & 0.436 & 0.242 & 1.000 & & & \\
\hline (16) GDP & -0.043 & 0.163 & 0.374 & -0.462 & -0.322 & -0.576 & 0.183 & -0.184 & -0.242 & -0.305 & 0.164 & 0.067 & 0.054 & 0.032 & 0.040 & 1.000 & & \\
\hline (17) $T R A D E$ & 0.154 & -0.194 & 0.050 & -0.023 & -0.124 & 0.143 & 0.215 & 0.168 & 0.167 & 0.132 & -0.143 & -0.157 & -0.012 & -0.064 & -0.061 & -0.220 & 1.000 & \\
\hline (18) DUM_LAW & -0.023 & -0.073 & -0.309 & 0.268 & -0.066 & 0.142 & 0.074 & 0.192 & 0.091 & 0.178 & -0.270 & -0.060 & -0.034 & -0.039 & -0.018 & -0.144 & 0.277 & 1.000 \\
\hline
\end{tabular}

(1) This table reports Pearson correlations among variables; (2) Correlations in bold are significant within the 5 percent level; (3) TAXAVOIDANCE is the worldwide GAAP ETR multiplied by negative one; TAX is an indicator variable for tax incentives equaling 1 if the average tax rate of the subsidiaries is lower than the tax rate of the parent of the group, and 0 otherwise; $P \_U A I, P \_I D V, P \_M A S$, and P_PDI are Hofstede's cultural-dimension-index scores of the home country of the parent of the group; S_UAI, S IDV , S_MAS, and S_PDI are the average cultural-dimension-index scores of the home countries of the subsidiaries of the group; $N$ SUUB the natural logarithm of the number of subsidiaries of the group plus one; SIZE is the natural logarithm of the total assets of the group; ROA is the ratio of the group's pre-tax income to group i's total assets in the previous year; INT is the ratio of the group's intangibles to the group's total assets in the previous year; SALESGR is the ratio of the group's sales to the group's sales in the previous year minus one; GDP is the natural logarithm of the per-capita GDP of the home country of the parent of the group; TRADE is the natural logarithm of the amount of trade of the home country of the parent of the group.; DUM_LAW is an indicator variable equaling 1 if the home country of the parent of the group adopts civil law and 0 if it adopts common law. 


\subsection{Hypothesis Testing}

Column [A] in Table 6 illustrates the main regression results for the hypotheses. Consistent with the first hypothesis, the coefficient on $P_{-} U A I$ is significantly negative $(-0.027)$ at the 1 percent level. This result indicates that MNCs headquartered in countries with high uncertainty avoidance engage in tax-avoidance activities to a lesser extent than those headquartered in countries with low uncertainty avoidance. Specifically, a one-point increase in the UAI score of the parent countries, on average, increases the worldwide GAAP ETR of MNCs by $2.7 \%$. These results are inconsistent with the positive association between uncertainty avoidance and individual perceptions of tax avoidance found by Tsakumis et al. [6] and Richardson [8]. One potential reason for these conflicting results is the significant political, and reputational costs faced by MNCs when tax avoidance is revealed (Hanlon and Slemrod [40]; Graham et al. [41]). Since MNCs are in a much more complex position than individuals when evaluating the marginal benefits and costs of tax avoidance, the nature of uncertainty avoidance of a country may affect the tax-avoidance behavior of individuals and MNCs differently. To summarize, under the multinational framework, MNCs headquartered in countries with strong uncertainty avoidance are not likely to engage in aggressive tax planning to minimize unexpected challenges by tax authorities.

The coefficient on $P_{-} I D V$ is significantly negative (-0.044). A negative association between the IDV score and tax avoidance implies that a higher level of individualism (collectivism) leads to a lower (higher) level of tax avoidance. These findings are consistent with the second hypothesis, as well as findings of Tsakumis et al. [6] and Richardson [8] that individuals in collectivist countries are involved in a higher level of tax avoidance because they do not view legal norms as universal and tend to override written laws. Consistent with the findings for individuals, MNCs in collectivist countries also engage in tax avoidance to a greater extent than those in individualist countries.

The coefficient on $P_{-} M A S$ is significantly positive (0.004) at the 1 percent level, supporting the third hypothesis. The results are consistent with the finding by Husted [11] that more masculine countries with higher preferences for achievement, heroism, assertiveness and material rewards for success tend to participate in corruption to achieve their goals. Therefore, contrary to the traditional view that masculinity decreases tax avoidance by individuals, the present study finds that MNCs in countries with higher masculinity (lower femininity) participate in more aggressive tax avoidance to achieve higher performance than those in less-masculine countries.

Lastly, the coefficient on $P_{-} P D I$ is significantly negative $(-0.009)$ at the 1 percent level. The last hypothesis is, therefore, supported. Since countries with high PDI scores tend to be less sensitive to fairness, accept a hierarchical order, and require no further justification for inequalities of power, the results indicate that MNCs in countries that are less sensitive to fairness engage in tax avoidance to a lesser extent than those in countries where individuals are highly sensitive to fairness. These results are generally consistent with Hofstede [12].

Next, the present study further investigates the individual effects of the cultures of subsidiary countries on tax avoidance. Column [B] in Table 6 illustrates the estimates for Equation (2). Only the coefficient of $S_{-} M A S$ is marginally significant at the 10 percent level. However, the coefficient sign of S_MAS is opposite to that found from the parent countries' cultural dimension index.

Column [C] in Table 6 reports the regression results of Equation (3), which examines the combined effects of the cultures of the parent and subsidiary countries. The estimates in Column [C] generally remain consistent with those in Columns [A] and [B]; the coefficients on Hofstede's dimensions of the parent countries (P_CULTURE) are all significant, and the coefficients on Hofstede's dimensions of the subsidiary countries (S_CULTURE) are insignificant or marginally significant. This study further compares the coefficient of each P_CULTURE variable with the coefficient of the corresponding S_CULTURE variable. The results show that the coefficients on P_CULTURE are significantly larger than those of S_CULTURE at the 1 the percent level. In summary, the cultural features of the parent have a stronger influence on group-level tax avoidance than those of the subsidiaries. Statistical inferences are largely unchanged when standard errors are clustered by industry-year or headquartered country-year. 
The tax-rate difference between the parent and subsidiary countries also significantly affects the level of tax avoidance by MNCs; the coefficient on TAX is positive and significant at the 1 percent level in Columns [A] to [C]. This result indicates that MNCs with subsidiaries in lower-tax-rate jurisdictions, on average, engage in a higher level of tax avoidance by shifting income from high-tax-rate parent countries.

Table 6. Regression results for Equations (1), (2), and (3).

\begin{tabular}{|c|c|c|c|c|c|c|c|}
\hline \multirow{2}{*}{ Variables } & \multirow{2}{*}{ Pred. } & \multicolumn{2}{|c|}{ [A] Eq. (1) } & \multicolumn{2}{|c|}{ [B] Eq. (2) } & \multicolumn{2}{|c|}{ [C] Eq. (3) } \\
\hline & & Coeff & t-stat & Coeff & t-stat & Coeff & t-stat \\
\hline & 6.506 & $5.080^{* * *}$ & 1.156 & $4.059^{* * *}$ & 6.446 & $5.032^{* * *}$ \\
\hline $\begin{array}{c}\text { Intercept } \\
T A X\end{array}$ & + & 0.018 & $4.981^{* * *}$ & 0.016 & $4.349^{* * *}$ & 0.016 & $4.349^{* * *}$ \\
\hline P_UAI & - & -0.027 & $-5.084^{* * *}$ & & & -0.026 & $-5.033 * * *$ \\
\hline$P_{-} I D V$ & - & -0.044 & $-5.176 * * *$ & & & -0.043 & $-5.115 * * *$ \\
\hline$P \_M A S$ & + & 0.004 & $4.683 * * *$ & & & 0.004 & $4.699 * * *$ \\
\hline P_PDI & - & -0.009 & $-5.229 * * *$ & & & -0.009 & $-5.201 * * *$ \\
\hline S_UAI & $?$ & & & -0.000 & -0.027 & -0.000 & -0.027 \\
\hline S_IDV & $?$ & & & -0.000 & -0.972 & -0.000 & -0.972 \\
\hline$S \_M A S$ & $?$ & & & -0.000 & $-1.685 *$ & -0.000 & $-1.685 *$ \\
\hline S_PDI & $?$ & & & 0.000 & 1.186 & 0.000 & 1.186 \\
\hline N_SUB & + & 0.005 & 1.807 * & 0.005 & 1.774 * & 0.005 & 1.774 * \\
\hline$\overline{S I Z E}$ & $?$ & 0.009 & $8.210^{* * *}$ & 0.009 & $8.279^{* * *}$ & 0.009 & $8.279^{* * *}$ \\
\hline$R O A$ & $?$ & 0.239 & $24.428^{* * *}$ & 0.239 & $24.380^{* * *}$ & 0.239 & $24.380^{* * * *}$ \\
\hline$I N T$ & + & -0.175 & $-7.160^{* * *}$ & -0.175 & $-7.162 * * *$ & -0.175 & $-7.162 * * *$ \\
\hline SALESGR & + & -0.005 & $-6.836^{* * *}$ & -0.005 & $-6.832 * * *$ & -0.005 & $-6.832 * * *$ \\
\hline$G D P$ & - & -0.118 & $-5.482 * * *$ & -0.118 & $-5.461^{* * *}$ & -0.118 & $-5.461^{* * *}$ \\
\hline TRADE & - & -0.097 & $-4.174^{* * *}$ & -0.097 & $-4.161^{* * *}$ & -0.097 & $-4.161^{* * *}$ \\
\hline DUM_LAW & - & -1.039 & $-4.979^{* * *}$ & 0.175 & $5.624^{* * *}$ & -1.025 & $-4.910 * * *$ \\
\hline \multicolumn{2}{|c|}{$\mathrm{N}$} & \multicolumn{2}{|c|}{36,235} & \multicolumn{2}{|c|}{36,235} & \multicolumn{2}{|c|}{36,235} \\
\hline \multicolumn{2}{|c|}{ Adj. $R^{2}$} & \multicolumn{2}{|c|}{0.173} & \multicolumn{2}{|c|}{0.174} & \multicolumn{2}{|c|}{0.174} \\
\hline \multicolumn{2}{|c|}{ F-value } & & $* * *$ & & $3 * * *$ & 51. & $* * * * * *$ \\
\hline Test $\mathrm{H}_{\mathrm{O}}: P_{-}$ & $=S \_U A I$ & & & & & & $7 * * *$ \\
\hline Test $\mathrm{H}_{\mathrm{O}}: P$ & $=S \_I D V$ & & & & & & $1 * * *$ \\
\hline Test $\mathrm{H}_{\mathrm{O}}: P_{-}$ & $=S \_M A S$ & & & & & & $0 * * *$ \\
\hline Test $\mathrm{H}_{\mathrm{O}}: P$ & $=S \_P D I$ & & & & & & $7 * * *$ \\
\hline
\end{tabular}

$(1)^{*}, * *$ and ${ }^{* * *}$ indicate statistical significance at the 10 percent, 5 percent, and 1 percent levels, respectively; (2) The robust t-statistics reported for these regressions are based on robust standard errors clustered by MNC groups; (3) Test $\mathrm{H}_{\mathrm{O}}$ shows the results for testing the null hypothesis that the coefficients on P_CULTURE equal the coefficients on the corresponding S_CULTURE; (4) TAXAVOIDANCE is the worldwide GAAP ETR multiplied by negative one; TAX is an indicator variable for tax incentives equaling 1 if the average tax rate of the subsidiaries is lower than the tax rate of the parent of the group, and 0 otherwise; $P_{-} U A I, P \_I D V, P \_M A S$, and P_PDI are Hofstede's cultural-dimension-index scores of the home country of the parent of the group; $S_{-} U A I, S_{-} I D V, S \_M A S$, and S_PDI are the average cultural-dimension-index scores of the home countries of the subsidiaries of the group; $N_{-} S U B$ the natural logarithm of the number of subsidiaries of the group plus one; SIZE is the natural logarithm of the total assets of the group; $R O A$ is the ratio of the group's pre-tax income to group $i$ 's total assets in the previous year; INT is the ratio of the group's intangibles to the group's total assets in the previous year; SALESGR is the ratio of the group's sales to the group's sales in the previous year minus one; GDP is the natural logarithm of the per-capita GDP of the home country of the parent of the group; TRADE is the natural logarithm of the amount of trade of the home country of the parent of the group.; DUM_LAW is an indicator variable equaling 1 if the home country of the parent of the group adopts civil law and 0 if it adopts common law.

The coefficient on N_SUB is significant and positive, consistent with the prediction. This implies that MNCs with a larger number of affiliates engage in a higher level of tax avoidance. Accordingly, tax authorities should pay more attention to MNCs with a large number of affiliates located in different countries. The coefficients on GDP, and TRADE are significantly negative, also consistent with the prediction. The results indicate that MNCs headquartered in less developed countries conduct tax avoidance to a greater extent than those headquartered in developed countries. This finding supports the anecdotal evidence that a large number of MNCs avoid taxes using tax havens with small economic 
size (e.g., Cayman Island, Virgin Island, Bermuda, etc.). The coefficient on DUM_LAW is significantly negative and consistent with the prediction. Therefore, MNCs located in countries adopting common law engage in a higher level of tax avoidance than those in countries adopting civil law.

The coefficients on SIZE and ROA show significantly positive signs. These results provide important evidence that tax avoidance follows economies of scale and that more-profitable MNCs tend to have higher incentives for tax reduction.

Inconsistent with the prediction, INT and SALESGR are negatively related to the dependent variable TAXAVOIDANCE. These results provide evidence that INT and SALESGR can be a measure of a growth company, as a growth company generally has a high sales growth ratio and high interests in investment in intangibles. In this regard, the results for INT and SALESGW can be interpreted as indicating that growth companies have less incentive to invest in tax planning (Bankman [69]; Chen et al. [67]; Robinson et al. [49]).

The results of these control variables provide important implications for the policymakers. By understanding the features of MNCs engaging in the higher level of tax avoidance, policymakers can establish more effective and sophisticated regulations for tax avoidance.

\subsection{Robustness Tests}

\subsubsection{Cross-sectional and Time-Series Dependence}

Because this study uses panel data, the results of this study may be subject to both cross-sectional and time-series dependence. For this reason, the study re-examines the main analysis by estimating equations (1) through (3) using the panel regression with random-effects and feasible generalized least squares (FGLS), respectively. Because Hofstede's dimension scores are constant over time, panel regression with the fixed-effects are not applicable to this analysis.

Column A in Table 7 reports the estimates for panel regression with the random-effects. The results remain constant under the random-effects model. Column B in Table 7 shows the estimates for FGLS under the assumption of heteroskedasticity. The results are generally consistent for P_CULTURE variables, although some inconsistent results are observed for S_CULTURE variables. This study uses the panel data with time gaps. For this reason, FGLS assuming autocorrelation is not applicable. Nevertheless, equations are estimated using FGLS under the assumption of autocorrelation by ignoring the time gap. Untabulated results show consistent estimates.

In summary, the results of these robustness tests support that cross-sectional and time-series dependence problem does not significantly influence the main results of this study.

\subsubsection{Robustness of Hofstede's Cultural Dimensions}

The first robustness test is to check whether Hofstede's cultural dimensions are well-defined measures that represent the cultural aspects of each country. To determine the appropriateness of each of the four cultural dimensions, alternative measures that represent similar cultural aspects of countries are selected, and the correlations between each of the four Hofstede cultural dimensions and its alternative measure are estimated.

First, the total insurance gross premiums of the countries obtained from the OECD Statistics database is selected as an alternative measure of uncertainty avoidance. Because individuals with high uncertainty avoidance would be willing to pay a greater amount of insurance premiums to suppress any unexpected future risks, the uncertainty avoidance of countries is expected to have a positive correlation with the amount of insurance gross premiums. Consistent with the prediction, the UAI scores of the countries are estimated to be positively correlated (0.0675) with their corresponding total insurance gross premiums at the 1 percent level. 
Table 7. Estimates for random-effects model and feasible generalized least squares (FGLS).

\begin{tabular}{|c|c|c|c|c|c|}
\hline \multirow[t]{2}{*}{ Variables } & \multirow[t]{2}{*}{ Pred. } & \multicolumn{2}{|c|}{$[A]$} & \multicolumn{2}{|c|}{$\begin{array}{c}\text { [B] } \\
\text { FGLS }\end{array}$} \\
\hline & & Coeff & t-stat & Coeff & t-stat \\
\hline Intercept & & 6.091 & $4.999^{* * *}$ & 6.689 & $17.580^{* * *}$ \\
\hline$T A X$ & + & 0.013 & $3.672 * * *$ & 0.017 & $19.701^{* * *}$ \\
\hline P_UAI & - & -0.025 & $-4.738^{* * *}$ & -0.028 & $-17.749 * * *$ \\
\hline P_IDV & - & -0.040 & $-4.765 * * *$ & -0.045 & $-17.886 * * *$ \\
\hline P_MAS & + & 0.004 & $4.506 * * *$ & 0.004 & $16.575 * * *$ \\
\hline P_PDI & - & -0.009 & $-4.991 * * *$ & -0.010 & $-18.409 * * *$ \\
\hline S_UAI & $?$ & -0.000 & -0.601 & 0.000 & $2.097 * *$ \\
\hline$S \_I D V$ & $?$ & -0.000 & -0.856 & -0.000 & $-5.690^{* * *}$ \\
\hline$S \_M A S$ & $?$ & -0.000 & -1.524 & -0.000 & $-7.654^{* * *}$ \\
\hline $\bar{S} \_P D I$ & $?$ & 0.000 & 0.843 & 0.000 & $6.212 * * *$ \\
\hline \multirow{2}{*}{\multicolumn{2}{|c|}{$\begin{array}{c}\text { Control variables, Year, Industry, and Country F.E. } \\
\mathrm{N}\end{array}$}} & \multicolumn{2}{|c|}{ Y } & \multicolumn{2}{|r|}{$\mathrm{Y}$} \\
\hline & & \multicolumn{2}{|c|}{36,235} & \multicolumn{2}{|c|}{36,235} \\
\hline \multicolumn{2}{|c|}{ Wald Chi-Squared } & \multicolumn{2}{|c|}{$3535.93^{* * *}$} & \multicolumn{2}{|c|}{$134.666 .08^{* * *}$} \\
\hline \multicolumn{2}{|c|}{ Test $H_{O}: P \_U A I=S \_U A I$} & \multicolumn{2}{|c|}{$22.32 * * *$} & \multicolumn{2}{|c|}{$315.81^{* * *}$} \\
\hline \multicolumn{2}{|c|}{ Test $\mathrm{H}_{\mathrm{O}}: P_{-} I D V=S \_I D V$} & \multicolumn{2}{|c|}{$22.57 * * *$} & \multicolumn{2}{|c|}{$318.46^{* * *}$} \\
\hline \multicolumn{2}{|c|}{ Test $\mathrm{H}_{\mathrm{O}}: P \_M A S=S \_M A S$} & & \multicolumn{2}{|c|}{$293.80^{* * *}$} \\
\hline \multicolumn{2}{|c|}{ Test $\mathrm{H}_{\mathrm{O}}: \bar{P}_{-} P D I=S_{-} P D I$} & \multicolumn{2}{|c|}{$25.37 * * *$} & \multicolumn{2}{|c|}{$349.10^{* * *}$} \\
\hline
\end{tabular}

$(1)^{*}, * *$, and ${ }^{* * *}$ indicate statistical significance at the 10 percent, 5 percent, and 1 percent levels, respectively; (2) Columns A and B show estimates for random-effect model, and estimates for FGLS assuming heteroskedasticity, respectively; (3) Test $\mathrm{H}_{\mathrm{O}}$ shows the results for testing the null hypothesis that the coefficients on P_CULTURE equal the coefficients on the corresponding S_CULTURE; (4) TAXAVOIDANCE is the worldwide GAAP ETR multiplied by negative one; TAX is an indicator variable for tax incentives equaling 1 if the average tax rate of the subsidiaries is lower than the tax rate of the parent of the group, and 0 otherwise; $P_{-} U A I, P_{-} I D V, P_{-} M A S$, and $P_{-} P D I$ are Hofstede's cultural-dimension-index scores of the home country of the parent of the group; S_UAI, S_IDV, S_MAS, and S_PDI are the average cultural-dimension-index scores of the home countries of the subsidiaries of the group.

For individualism (IDV), the marriage rate of countries is determined as an alternative measure. Because highly individualist (collectivist) countries are likely to have lower (higher) marriage rates, the IDV scores and marriage rates of countries are expected to have a negative correlation. The correlation is estimated to be -0.1167 at the 1 percent level.

One feature of masculine countries is that economic activities by men prevail over those by women because of traditional perceptions of gender roles. Based on this idea, the difference in the employment rates of males and females is used as an alternative measure of masculinity (MAS). Specifically, the gap (male-less-female) in the employment-to-population ratio of countries obtained from the OECD Statistics database is used. The correlation between the MAS scores of countries and the gap in the male and female unemployment ratios is estimated to be positive (0.5661) at the 1 percent level. It is notable that the correlation is significantly high. These results confirm that MAS is an appropriate measure to represent perceptions of gender roles.

Lastly, the Gini coefficient is used as an alternative measure for PDI because, similar to PDI, the Gini coefficient represents inequality of income or wealth. A high (low) Gini coefficient indicates high inequality in income or wealth distribution. Individuals in countries with a high PDI are generally tolerant of inequality in power. Because members of these societies are also likely to be tolerant of economic inequality, the PDI score is expected to have a positive correlation with the Gini coefficient. Consistent with the prediction, the correlation between the PDI score and Gini coefficient is estimated to be 0.0963 at the 1 percent level.

In summary, these correlation tests between Hofstede's four cultural dimensions and their alternative measures provide indirect, but intuitive and robust support for the appropriateness of using Hofstede's cultural dimensions as a measure of the cultural features of countries. 


\subsubsection{Analysis of the Long-run ETR}

In this robustness test, the dependent variable TAXAVOIDANCE is calculated using the long-run worldwide GAAP ETR instead of the single-year worldwide GAAP ETR to examine the influence of national culture on long-term tax planning by MNCs. The dependent, independent and control variables are all converted into long-run variables of 5 years. The total number of observations is reduced to 3,617 group years after excluding observations with missing values and negative pretax earnings during the sample period of 2011-2015.

Insignificant coefficients on Hofstede's four cultural dimensions are observed for parent countries ( $P_{-} I D V, P_{-} U A I, P_{-} M A S$, and $P_{-} P D I$ ) based on the untabulated results of this robustness test. That is, the cultural features of parents do not affect long-term tax planning by MNCs. However, the results of this test should be interpreted with caution for the following reasons. First, long-run ETR may not capture tax-avoidance activities because the measure smooths year-to-year volatility in annual ETR. Second, many unobservable confounding factors influence ETR from a long-term perspective (Dyreng et al. [70]). Third, the statistical power of this robustness test is relatively low because the results may reflect the tax-avoidance activities of only profitable MNCs with positive pretax earnings for five years.

\subsubsection{Analysis of Sample-selection Bias}

The US and Japan applied high statutory tax rates for the period of 2008 to 2015. High tax rates lead the US and Japanese MNCs to have high motivations for tax avoidance. Thus, the US and Japanese MNCs in the final sample used in this study may cause sample-selection bias. To examine any potential bias, due to the US and Japanese MNCs in the results of this study, the same analysis is conducted again, excluding the US and Japanese MNCs. The sample of MNCs reduces to 35,344 $(33,248)$ observations when the US (Japanese) MNCs are excluded. Consistent results are obtained at the 1 percent level. Therefore, the results of this study are robust to sample-selection bias.

\subsection{Additional Tests}

MNCs tend to establish subsidiaries in countries whose cultural features are similar to those of the home country to minimize uncertainties and risks associated with their business activities. MNCs with subsidiaries in countries with significantly different cultural backgrounds from the home country would have significantly high tax incentives or other nontax incentives, such as low wages, high market demands, technology opportunities, etc. The purpose of this additional analysis is to identify the tax-avoidance behaviors of MNCs that establish subsidiaries in countries with significantly different cultural features from the home country, specifically, to check whether these MNCs have either high tax incentives or high nontax incentives.

First, we divide our sample into two groups: MNCs whose parent and subsidiary countries differ in cultural aspects (HETEROGEN), and MNCs whose parents and subsidiary countries are similar in cultural aspects (HOMOGEN). To determine each of the two groups, we subtract the scores of S_CULTURE from P_CULTURE to calculate DIFF_CULTURE. MNCs with extremely high or low values of DIFF_CULTURE are classified as the HETEROGEN group because their subsidiaries differ from their parents in terms of cultural characteristics. DIFF_CULTURE for each dimension is classified into quintiles. MNCs belonging to the first and last quintile groups have a large spectrum of cultural features. Therefore, MNCs having a large spectrum of cultural features in more than three of four dimensions are determined as the HETEROGEN group. The remaining MNCs are classified into the HOMOGEN group. As such, we identify the HETEROGEN group of MNCs as those having more than three dimensions ranked in the highest and lowest quintiles based on DIFF_CULTURE.

Next, the main regression analysis is re-examined using a subsample of HETEROGEN and a subsample of $H O M O G E N$, respectively, to compare the coefficients on the tax incentive variable $T A X$. The coefficients on TAX provide information on the magnitude of MNCs' tax-avoidance activities based on tax incentives. 
Table 8 provides the results for the coefficient on TAX for the HETEROGEN and HOMOGEN groups. The magnitude of tax avoidance by MNCs in the HOMOGEN group (0.022) is slightly higher than that of MNCs in the HETEROGEN group (0.012). The difference between the magnitudes of tax avoidance in the two subsamples is estimated to be marginally significant. Therefore, we indirectly conclude that MNCs with subsidiaries in countries whose cultural backgrounds differ significantly from that of the home country (i.e., heterogeneous MNCs) are generally motivated by high nontax incentives (e.g., opportunities in wages, markets, technologies, etc.) rather than tax incentives (i.e., tax rate differences between the parent and subsidiary countries). Moreover, it can be construed that MNCs whose parents and subsidiaries operate in countries with similar cultural aspects (i.e., homogeneous MNCs) are likely to engage in tax-motivated income shifting to a greater extent than heterogeneous MNCs, due to the relatively lower level of nontax risks.

Table 8. Comparison of coefficients on TAX for the two MNC groups.

\begin{tabular}{|c|c|c|}
\hline & $\begin{array}{c}\text { HETEROGEN }(\mathrm{N}=20,840) \\
{[\mathrm{A}]}\end{array}$ & $\begin{array}{c}\text { HOMOGEN }(\mathrm{N}=15,395) \\
{[\mathrm{B}]}\end{array}$ \\
\hline Coefficient on $T A X$ & 0.012 & 0.022 \\
\hline t-stat & $3.26^{* * *}$ & $5.16^{* * *}$ \\
\hline F-Value: Coefficient on TAX & \multicolumn{2}{|c|}{$3.22 *$} \\
\hline
\end{tabular}

(1) ${ }^{*}$ and ${ }^{* * *}$ indicate statistical significance at the 10 percent, and 1 percent levels, respectively; (2) The HETEROGEN group of MNCs comprises MNCs with more than three dimensions ranked in the highest and lowest quintiles based on DIFF_CULTURE. DIFF_CULTURE is defined as P_CULTURE minus S_CULTURE. Any MNCs that do not belong to the HETEROGEN group are classified as the HOMOGEN group; (3) The coefficient on TAX is determined by estimating the pooled OLS regression using Equation (3), where the dependent variable TAXAVOIDANCE is measured as the worldwide GAAP ETR multiplied by negative one, and the independent variable TAX is an indicator variable for tax incentives equaling 1 if the average tax rate of the subsidiaries is lower than the tax rate of the parent of the group, and 0 otherwise.

\section{Conclusions}

Aggressive tax avoidance by MNCs has attracted public attention and criticism in recent years. In 2015, G20 financial ministers endorsed a package of measures to tackle MNCs' attempts to illegally reduce taxes under the OECD's BEPS project. Because tax avoidance is one of the deterring factors in building a sustainable economy, policymakers and tax authorities of countries should understand the determinants of MNCs' tax avoidance to secure sustainability. However, nontax determinants of tax avoidance have rarely been explored. For this reason, this study examines whether and to what extent national culture is associated with the level of MNCs' tax avoidance.

This study provides empirical evidence regarding the association between culture and MNCs' tax-avoidance behavior. Specifically, the study finds that the uncertainty avoidance, individualism, and power distance dimensions of countries decrease the level of MNCs' tax avoidance, whereas, the masculinity dimension of countries increases the level of MNCs' tax avoidance. The study also finds that the cultural features of the parent generally have a stronger influence on tax avoidance than those of the subsidiaries.

These findings have important implications for researchers and policymakers. This study is one of a few to investigate the effects of national culture. The findings of this study suggest that the cultural features of parent countries are significant determinants of tax avoidance by MNCs. Therefore, policymakers in each country should consider the cultural aspects of their countries when designing and predicting the effectiveness of anti-avoidance regulations. Furthermore, policymakers may introduce regulations restricting cultural features that are positively related to tax avoidance to limit tax avoidance. For example, tax avoidance by MNCs in a country with low uncertainty avoidance may be reduced if tax authorities impose a significant penalty on MNCs when their tax-avoidance behaviors are revealed. Introducing sophisticated anti-avoidance rules in consideration of cultural effects on tax avoidance will be attributed to obtaining sustainable economic growth. 
In addition to its multiple contributions, certain limitations of this study must be acknowledged. First, the limitations of the Orbis database may weaken the robustness of the results of this study. Specifically, the final data used in this study will omit affiliates if affiliates are established or acquired by another affiliate during the analysis period as a result of business restructuring. Second, U.S. observations are generally excluded from the final sample because the Orbis database discloses consolidated financial data of US firms only. The lack of US observations may affect the results of this study. Third, various measures of tax avoidance should be considered to reduce measurement errors and ensure the robustness of the results. Lastly, because of the complex and subjective feature of culture, Hofstede's four cultural dimensions used in this study may not measure the cultural aspects of countries with complete accuracy. This may influence the estimates of the study. Therefore, careful interpretation is required before generalizing the results of this study.

Author Contributions: Methodology, Y.J.L.; Writing—original draft, J.S.Y.

Funding: This research received no external funding.

Acknowledgments: We are grateful for helpful comments and suggestions from Dan Simunic at the University of British Columbia and K. K. Raman from the University of Texas at San Antoni at the 2019 JCAE Doctoral Consortium.

Conflicts of Interest: The authors declare no conflict of interest.

\section{References}

1. Guiso, L.; Sapienza, P.; Zingales, L. Does culture affect economic outcomes? J. Econ. Perspect. 2006, 20, $23-48$. [CrossRef]

2. North, D.C. Institutions. J. Econ. Perspect. 1991, 5, 97-112. [CrossRef]

3. Alesina, A.; Giuliano, P. Culture and institutions. J. Econ. Lit. 2015, 53, 898-944. [CrossRef]

4. Brochet, F.; Miller, G.S.; Naranjo, P.; Yu, G. Managers' cultural background and disclosure attributes. Account. Rev. 2018, 94, 57-86. [CrossRef]

5. Doidge, C.; Karolyi, G.A.; Stulz, R.M. Why do countries matter so much for corporate governance? J. Financ. Econ. 2007, 86, 1-39. [CrossRef]

6. Tsakumis, G.T.; Curatola, A.P.; Porcano, T.M. The relation between national cultural dimensions and tax evasion. J. Int. Account. Audit Tax. 2007, 16, 131-147. [CrossRef]

7. Richardson, G. Determinants of tax evasion: A cross-country investigation. J. Int. Account. Audit Tax. 2006, 15, 150-169. [CrossRef]

8. Richardson, G. The relationship between culture and tax evasion across countries: Additional evidence and extensions. J. Int. Account. Audit Tax. 2008, 17, 67-78. [CrossRef]

9. Bame-Aldred, C.W.; Cullen, J.B.; Martin, K.D.; Parboteeah, K.P. National culture and firm-level tax evasion. J. Bus. Res. 2013, 66, 390-396. [CrossRef]

10. Hofstede, G. Culture's Consequences: International Differences in Work-related Values; Sage Publications: Thousand Oaks, CA, USA, 1984; Volume 5.

11. Husted, B.W. Wealth, culture, and corruption. J. Int. Bus. Stud. 1999, 30, 339-359. [CrossRef]

12. Hofstede, G. Dimensionalizing cultures: The Hofstede model in context. Online Read. Psychol. Cult. 2011, 2, 8. [CrossRef]

13. Bird, R.; Davis-Nozemack, K. Tax avoidance as a sustainability problem. J. Bus. Ethics 2018, 151, 1009-1025. [CrossRef]

14. Law, K.K.; Mills, L.F. Taxes and financial constraints: Evidence from linguistic cues. J. Account. Res. 2015, 53, 777-819. [CrossRef]

15. Edwards, A.; Schwab, C.; Shevlin, T. Financial constraints and cash tax savings. Account. Rev. 2015, 91, 859-881. [CrossRef]

16. Riahi-Belkaoui, A. Relationship between tax compliance internationally and selected determinants of tax morale. J. Int. Account. Audit Tax. 2004, 13, 135-143. [CrossRef]

17. Picur, R.D.; Riahi-Belkaoui, A. The impact of bureaucracy, corruption and tax compliance. Rev. Account. Financ. 2006, 5, 174-180. [CrossRef] 
18. Akhtar, S.; Akhtar, F.; John, K.; Wong, S.-W. Multinationals' tax evasion: A financial and governance perspective. J. Corp. Financ. 2019, 57, 35-62. [CrossRef]

19. Alm, J.; Sanchez, I.; De Juan, A. Economic and noneconomic factors in tax compliance. Kyklos 1995, 48, 1-18. [CrossRef]

20. Cummings, R.C.; Martinez-Vazquez, J.; McKee, M.; Torgler, B. Effects of culture on tax compliance: A cross check of experimental and survey evidence. Work. Pap. 2004. [CrossRef]

21. Alm, J.; Torgler, B. Culture differences and tax morale in the United States and in Europe. J. Econ. Psychol. 2006, 27, 224-246. [CrossRef]

22. Gray, S.J.; Vint, H.M. The impact of culture on accounting disclosures: Some international evidence. Asia Pac J. Account. 1995, 2, 33-43. [CrossRef]

23. Hope, O.K. Firm-level disclosures and the relative roles of culture and legal origin. J. Int. Financ. Manag. Account. 2003, 14, 218-248. [CrossRef]

24. Hussein, M.E. A comparative study of cultural influences on financial reporting in the US and the Netherlands. Int. J. Account. 1996, 31, 95-120. [CrossRef]

25. Chan, K.H.; Lin, K.Z.; Mo, P.L.L. An empirical study on the impact of culture on audit-detected accounting errors. Auditing J. Pract. Theory 2003, 22, 281-295. [CrossRef]

26. Zhang, M.; Zhang, W.; Zhang, S. National culture and firm investment efficiency: International evidence. Asia Pac J. Account. 2016, 23, 1-21. [CrossRef]

27. OECD. Action Plan on Base Erosion and Profit Shifting; OECD Publishing: Paris, France, 2013.

28. Cattell, R.B. The dimensions of culture patterns by factorization of national characters. J. Abnorm. Soc. Psychol. 1949, 44, 443. [CrossRef]

29. Gregg, P.M.; Banks, A.S. Dimensions of political systems: Factor analysis of a cross-polity survey. Am. Polit. Sci. Rev. 1965, 59, 602-614. [CrossRef]

30. Adelman, I.; Morris, C.T. Society, Politics \& Economic Development; A Quantitative Approach; Johns Hopkins Press: Baltimore, MD, USA, 1967.

31. Lynn, R. Personality and National Character; Pergamon Press: Oxford, UK, 1971.

32. Lynn, R.; Hampson, S.L. National differences in extraversion and neuroticism. Br. J. Clin. Psychol. 1975, 14, 223-240. [CrossRef]

33. Hoftede, G.; Hofstede, G.J.; Minkov, M. Cultures and Organizations: Software of the Mind: Intercultural Cooperation and Its Importance for Survival; McGraw-Hill: New York, NY, USA, 2010.

34. Clotfelter, C.T. Tax evasion and tax rates: An analysis of individual returns. Rev. Econ. Stat. 1983, 65, 363-373. [CrossRef]

35. Milliron, V.; Toy, D. Tax compliance: An investigation of key features. J. Am. Tax. Assoc. 1988, 9, 84-104.

36. Collins, J.H.; Milliron, V.C.; Toy, D.R. Determinants of tax compliance: A contingency approach. J. Am. Taxat. Assoc. 1992, 14, 1-29.

37. Hofstede, G. Culture's Consequences: Comparing Values, Behaviors, Institutions and Organizations across Nations; Sage Publications: Thousand Oaks, CA, USA, 2001.

38. McDaniel, P.R.; Surrey, S.S. Tax Expenditures; Harvard University Press: Cambridge, MA, USA, 1985.

39. Wearing, A.; Headey, B. The would-be tax evader: A profile. Austl. Tax F. 1997, 13, 3.

40. Hanlon, M.; Slemrod, J. What does tax aggressiveness signal? Evidence from stock price reactions to news about tax shelter involvement. J. Public Econ. 2009, 93, 126-141. [CrossRef]

41. Graham, J.R.; Hanlon, M.; Shevlin, T.; Shroff, N. Incentives for tax planning and avoidance: Evidence from the field. Account. Rev. 2013, 89, 991-1023. [CrossRef]

42. Dyreng, S.D.; Hoopes, J.L.; Wilde, J.H. Public pressure and corporate tax behavior. J. Account. Res. 2016, 54, 147-186. [CrossRef]

43. Sanders, D.L.; Wyndelts, R. An examination of tax practitioners' decisions under uncertainty. Adv. Tax. 1989, 2, 41-72.

44. De Simone, L.; Klassen, K.J.; Seidman, J.K. Unprofitable affiliates and income shifting behavior. Account. Rev. 2016, 92, 113-136. [CrossRef]

45. Petersen, M.A. Estimating standard errors in finance panel data sets: Comparing approaches. Rev. Financ. Stud. 2009, 22, 435-480. [CrossRef]

46. Atwood, T.; Drake, M.S.; Myers, J.N.; Myers, L.A. Home country tax system characteristics and corporate tax avoidance: International evidence. Account. Rev. 2012, 87, 1831-1860. [CrossRef] 
47. Atwood, T.; Lewellen, C. The complementarity between tax avoidance and manager diversion: Evidence from tax haven firms. Contemp. Account. Res. 2019, 36, 259-294. [CrossRef]

48. Gupta, S.; Newberry, K. Determinants of the variability in corporate effective tax rates: Evidence from longitudinal data. J. Account. Public Policy 1997, 16, 1-34. [CrossRef]

49. Robinson, J.R.; Sikes, S.A.; Weaver, C.D. Performance measurement of corporate tax departments. Account. Rev. 2010, 85, 1035-1064. [CrossRef]

50. Hanlon, M.; Heitzman, S. A review of tax research. J. Account. Econ. 2010, 50, 127-178. [CrossRef]

51. Dyreng, S.D.; Hanlon, M.; Maydew, E.L. Long-run corporate tax avoidance. Account. Rev. 2008, 83, 61-82. [CrossRef]

52. Mills, L.F.; Nutter, S.E.; Schwab, C.M. The effect of political sensitivity and bargaining power on taxes: Evidence from federal contractors. Account. Rev. 2012, 88, 977-1005. [CrossRef]

53. Klassen, K.; Lang, M.; Wolfson, M. Geographic income shifting by multinational corporations in response to tax rate changes. J. Account. Res. 1993, 31, 141-173. [CrossRef]

54. Hines, J.R., Jr.; Rice, E.M. Fiscal Paradise: Foreign Tax Havens and American Business. Q. J. Econ. 1994, 109, 149-182. [CrossRef]

55. Jacob, J. Taxes and transfer pricing: Income shifting and the volume of intrafirm transfers. J. Account. Res. 1996, 34, 301-312. [CrossRef]

56. Collins, J.; Kemsley, D.; Lang, M. Cross-jurisdictional income shifting and earnings valuation. J. Account. Res. 1998, 36, 209-229. [CrossRef]

57. Mills, L.F.; Newberry, K.J. Do foreign multinationals' tax incentives influence their US income reporting and debt policy? Natl. Tax J. 2004, 57, 89-107. [CrossRef]

58. Clausing, K.A. Tax-motivated transfer pricing and US intrafirm trade prices. J. Public Econ. 2003, 87, 2207-2223. [CrossRef]

59. Huizinga, H.; Laeven, L. International profit shifting within multinationals: A multi-country perspective. J. Public Econ. 2008, 92, 1164-1182. [CrossRef]

60. Klassen, K.J.; Laplante, S.K. The effect of foreign reinvestment and financial reporting incentives on cross-jurisdictional income shifting. Contemp. Account. Res. 2012, 29, 928-955. [CrossRef]

61. Merks, P.; Finnerty, C.; Pettricione, M.; Russo, R. Fundamentals of International Tax Planning; IBFD: Amsterdam, The Netherlands, 2007.

62. Heckemeyer, J.H.; Overesch, M. Multinationals' profit response to tax differentials: Effect size and shifting channels. Can. J. Econ. 2017, 50, 965-994. [CrossRef]

63. Davies, R.B.; Martin, J.; Parenti, M.; Toubal, F. Knocking on tax haven's door: Multinational firms and transfer pricing. Rev. Econ. Stat. 2018, 100, 120-134. [CrossRef]

64. Cristea, A.D.; Nguyen, D.X. Transfer pricing by multinational firms: New evidence from foreign firm ownerships. Am. Econ. J. 2016, 8, 170-202. [CrossRef]

65. Koh, Y.S.; Kim, J.H.; Choi, W.-W. A Study on Corporate Tax Avoidance. Korean J. Tax. Res. 2007, $24,9-40$.

66. Desai, M.A.; Hines, J.R., Jr. Expectations and expatriations: Tracing the causes and consequences of corporate inversions. Natl. Bur. Econ. Res. 2002, 55, 409-440.

67. Chen, S.; Chen, X.; Cheng, Q.; Shevlin, T. Are family firms more tax aggressive than non-family firms? J. Financ. Econ. 2010, 95, 41-61. [CrossRef]

68. La Porta, R.; Lopez-de-Silanes, F.; Shleifer, A.; Vishny, R. The quality of government. J. Law Econ. Organ. 1999, 15, 222-279. [CrossRef]

69. Bankman, J. The structure of Silicon Valley start-ups. UClA L. Rev. 1993, 41, 1737.

70. Dyreng, S.D.; Hanlon, M.; Maydew, E.L.; Thornock, J.R. Changes in corporate effective tax rates over the past 25 years. J. Financ. Econ. 2017, 124, 441-463. [CrossRef]

(C) 2019 by the authors. Licensee MDPI, Basel, Switzerland. This article is an open access article distributed under the terms and conditions of the Creative Commons Attribution (CC BY) license (http://creativecommons.org/licenses/by/4.0/). 